\section{Das Schloss ReInhardtsgrimma und SEINE BeWOHNER}

Marcus Köhler

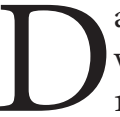

s vorliegende Heft wird sich nicht Bünaus, Schönbergs, Loss, Mangoldts und vollständig mit der seit dem Jahr Osterhausen bereits Stammsitze besaßen 1206 belegten Geschichte des Rit- oder dabei waren sie auszubauen, die Lietergutes Reinhardtsgrimma (Abb. 1) be- genschaft Reinhardtsgrimma jedoch wegen schäftigen können. In den bekannten Publi- ihrer günstigen Lage und der guten wirtkationen finden sich zwar zahlreiche Hin- schaftlichen Voraussetzungen wohl als lohweise auf die ältere Geschichte, diese müss- nenswertes Investitionsobjekt galt, wanderte ten jedoch - da oftmals ohne Quellenbeleg das Rittergut durch die Hände eines familiär - zunächst einer historisch-kritischen Revi- eng miteinander verbundenen Hofadels. Es sion unterzogen werden. Da sie aber keine ist deshalb möglicherweise kein Zufall, dass Rückschlüsse auf die garten- und land- die ersten wesentlichen Dokumente sich auf schaftshistorische Entwicklung Reinhardts- eine für Sachsen frühe Gutskartierung begrimmas versprechen, werden sie deshalb an ziehen, wobei ein von Balthasar Zimmerdieser Stelle weder aufgeführt noch über- mann signierter Plan vom 25. April 1628 prüft. ${ }^{1}$ Wichtig ist lediglich, dass sich als "das Haus Reinhartsgrym « und einen GraÜberbleibsel dieser Vorzeit die Reste der ben zum Schutz gegen feindliche Überfälle Burgruine Grimmenstein, die 1809 angeb- und zugleich wohl auch gegen das Eindrinlich vollständig »rasirt $^{2}$ wurde, und die Kir- gen des Grundwassers zeigt. ${ }^{3}$ Es ist zu verche erhalten haben, die jedoch zahlreiche muten, dass diese "Wasserburg « sich aus Umbauten erfuhr. Sie stehen aber nicht im mehreren Gebäuden zusammensetzte. Der Zentrum dieser Publikation, sondern das Graben, der recht groß gewesen sein muss, Schloss und die Gartenanlagen sowie die sie diente auch zur Fischzucht, heißt es doch im umgebende Kulturlandschaft. Die ersten re- »Erbregister über das Rittergut Reinhardtslevanten Auskünfte, die sich über entspre- grim [...] des Wohl Edlen Gestrengen Herrn chende Entwicklungen archivalisch belegen Johann ['Hanß'] Georg von Osterhausen lassen, weisen ins 17. Jahrhundert. Und an (1577-1627) auf Reinhardtsgrimm, Oberdiesem Punkt setzt auch unsere Geschichte und Niederlockwitz auch Nickern, Churein.

fürstl. Sächs. Ober-Cammer und Bergrath zu Dresden Anno 1624.«:

»Um das Schloß und Rittersitz Reinhartgrim mit seinen Eingebäuden, an Stuben, Cammern, gewölben Kellern und dergleichen $[\ldots]$ zieht sich ein Graben [...] darinn werden allerley an Karpffen, Würfflingen, rothe und Schwarze auch andere Speisefische gesetzt. «4

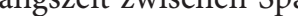
und Neuzeit prägte für eine längere Zeit heute ausgestorbene Familie von Karras (1415 bis ca. 1600), bevor diverse Besitzerwechsel die Geschichte Reinhardtsgrimma bestimmten, das überdies bis etwa 1630 auch

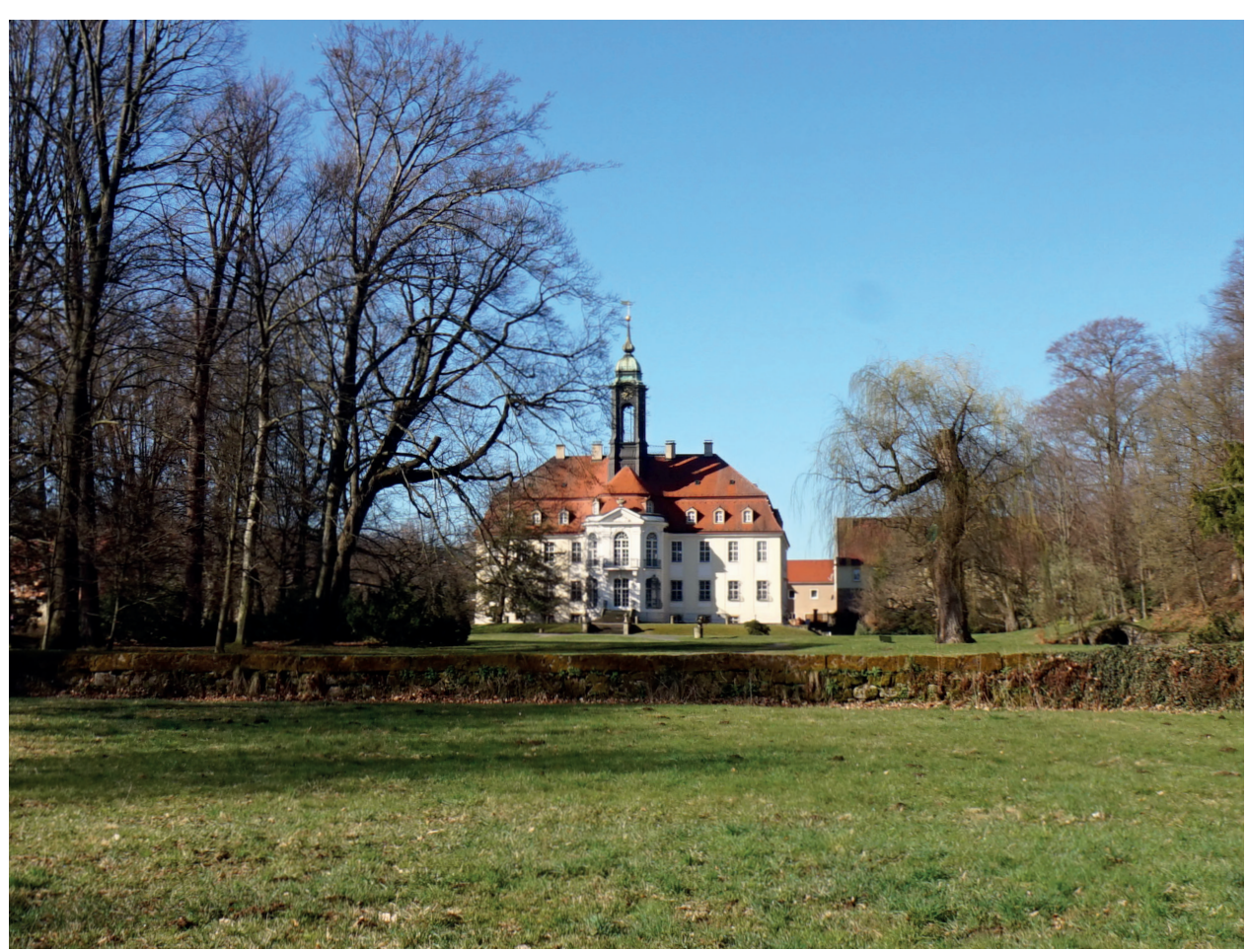

1 | Blick von der Gartenseite auf das Schloss Reinhardtsgrimma, Fotografie: Anja Gottschalk, April 2021.

Durch die Niederlegung eines solchen de- in den grundherrschaftlichen Gehölzen und taillierten Erbregisters, wurden damals Ländereien grasen durften. Die BewirtschafGrundlagen geschaffen, die Anfang des 17. tung orientierte sich an den naturräumliJahrhunderts die Gründung wirtschaftlich chen Gegebenheiten, weswegen sie sich einträglicher, familiärer Landsitze förderten. auch nicht beliebig ausbauen oder einstellen Diese Erbregister können als eine Art Orts- ließ und bis ins 19. Jahrhundert folglich auch satzung und Kataster verstanden werden. recht konstant blieb. Die "Grimmsche Sie waren oftmals so zukunftsorientiert, dass Heide«, die wahrscheinlich bereits in der sie in Teilen sachsenweit noch bis ins 19. zweiten Hälfte des 18. Jahrhunderts 5 aufgeJahrhundert hinein Rechte und Pflichten des forstet wurde, verdankt ihre Entstehung den Gutsherren, seiner Bediensteten aber auch kargen Böden und der Haltung von Schafen, der Einwohner festhielten und zu einem also Rahmenbedingungen, wie sie bereits Ausgleich verschiedenster Interessen, in den 250 Jahre vorher festgelegt und praktiziert durch die natürlichen und politischen Gege- wurden. Erst neue landwirtschaftliche und benheiten gesetzten Bedingungen, führen forstliche Methoden sowie diverse Hilfsmitsollten.

Eine Nebensächlichkeit mag hierfür spre- Produktion. Doch dazu später. noch aus zwei Teilen bestand (Ober- und Niederhof). Da die Besitzerfamilien wie die chen: Auf dem Nieder- und Oberhof zählte

man 1624 insgesamt 60 Melkkühe, sechs Aufgrund der beschriebenen günstigen TatPferde, 20 Schweine, Hühner Enten, Gänse, sachen setzte ab 1635 eine auf die Familie Tauben und 798 Schafe, die von Michaelis von Tettau bezogene Besitzerfolge ein, die (29. Oktober) bis Walpurgis (1. Mai) auf al- bis 1765 anhielt. 1643 vom Kurfürsten als len Feldern und Triften, danach jedoch nur dauerhaftes Lehen der Familie bestätigt, 
weist auch die heute noch vorhandene und wurde, bleibt trotz seines, vermutlich im Sievom ersten Tettauer vor Ort, Christoph benjährigen Krieg durch wichtige LieferFriedrich, über der Familiengruft ange- ungen vermehrten, Vermögens eine histobrachte Jahreszahl 1656 darauf hin, dass er risch eher schattenhafte Figur. Folgt man beabsichtigte, dort einen Stammsitz für den Akten des Appelationsgerichts, so nahm seine Familie zu gründen, was ihm auch gelang.

\section{Das Gut im 18. Jahrhundert}

Der Siebenjährige Krieg (1756-1763) hatte Sachsen schwer zugesetzt. Da die verfeindeten Armeen zwischen Reinhardtsgrimma und Maxen Ende 1759 Stellungen bezogen hatten und es schließlich zu einem für Preußen verlustreichen Gefecht kam, waren die Felder vernichtet und vermutlich auch Guts- und Bauernhöfe geplündert. Eine farbige Ansicht zeigt die Ebene, die sich zwischen den Dörfern erstreckt und taktisch den letzten Aufstellungsort im Erzgebirge markiert (Abb. 2).

Dies muss auch der Grund gewesen sein, Aus den Kirchenmatrikeln von Reinhardtswarum das 1635 vom Feldherrn Christoph grimma wird ersichtlich, dass im Februar Friedrich von Tettau (1602-1660) erwor- 1767 - »nachdem das alte als baufällig vorbene Reinhardtsgrimma, "wo er den Göttli- hero abgetragen und alsdann [ein anderes chen Segen seiner Wirtschafft reichlich ver- Schloss] neuerlich angeleget und eingerichspührte «, 7 von seinen Nachkommen ver- tet « wurde - Lippold die Vorgängerbauten kauft werden musste. Die Erben und Söhne vollkommen beseitigen ließ. ${ }^{12}$ Pfarrer Brückdes letzten Inhabers, des Kapitäns der Infan- ner beschreibt es mit seinen Worten: terie Otto Wilhelm von Tettau auf Toberitz (1697-1757) und seiner Frau Juliana Augusta geb. von Reibold - das waren August Wilhelm und Carl Christian von Tettau (1730$1805)^{8}$ sowie weitere sieben Geschwister veräußerten 1766 den Gutsbesitz. Die Übernahme des Rittergutes durch den bürgerlichen Johann Christoph Lippold (?-1780) war damals noch äußert ungewöhnlich, hing mit dem Erwerb doch ein Lehensrecht zusammen, das einst den Adel privilegierte und nunmehr auch auf Bürgerliche übertragen werden sollte. ${ }^{9}$

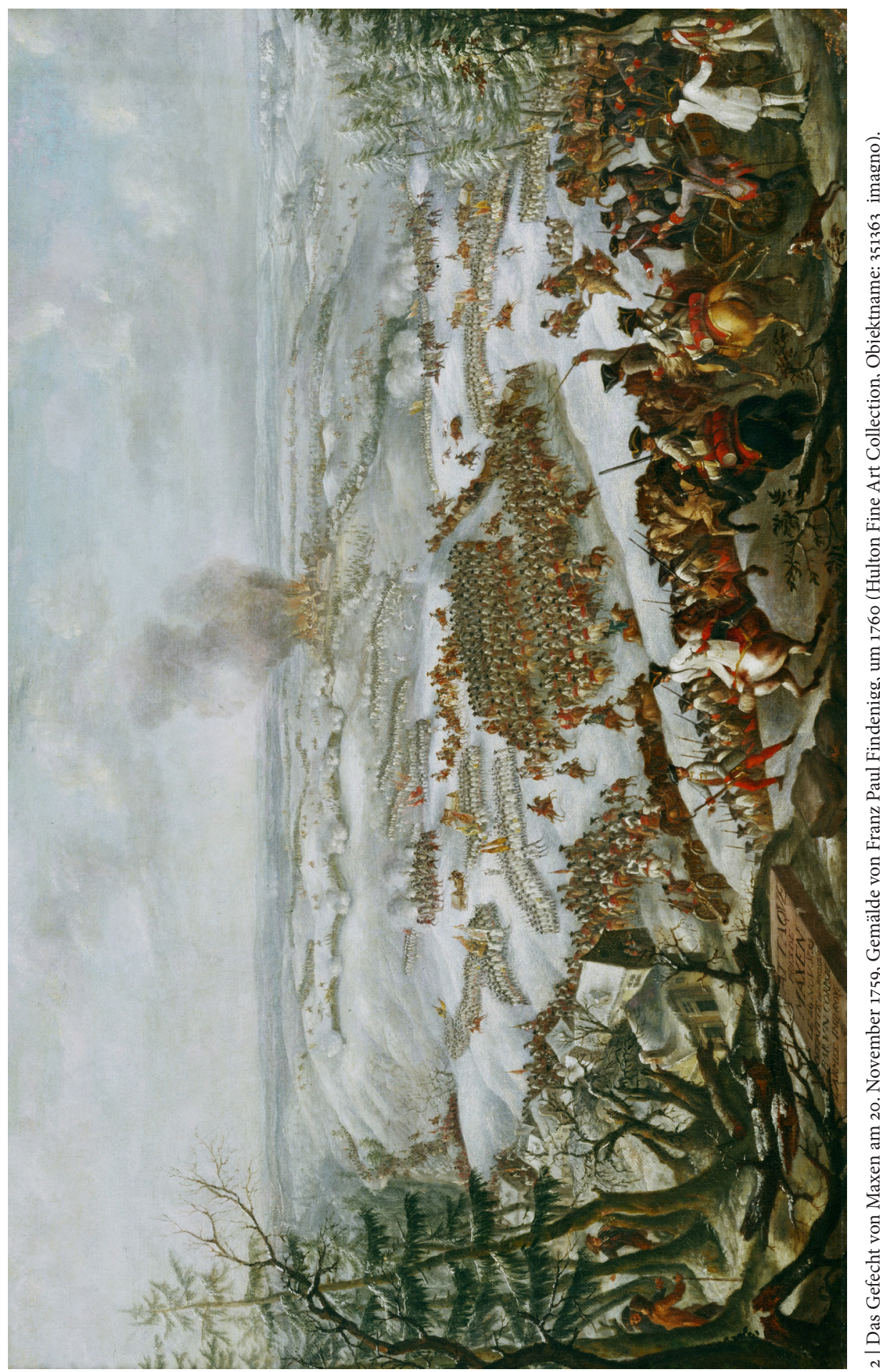

Lippold, der 1744 als »Hof-Kommissarius«, Eine Zuschreibung des von Lippold veran1750 als königlich-kurfürstlicher Commer- lassten Schlossneubaus an Johann Friedrich zien-Rath und später - da nicht adlig - nur Knöbel (1724-1792) findet sich schon 1784 als » Titular-Cammer-Rath « bezeichnet und ist umso glaubhafter, da der Baumeister 


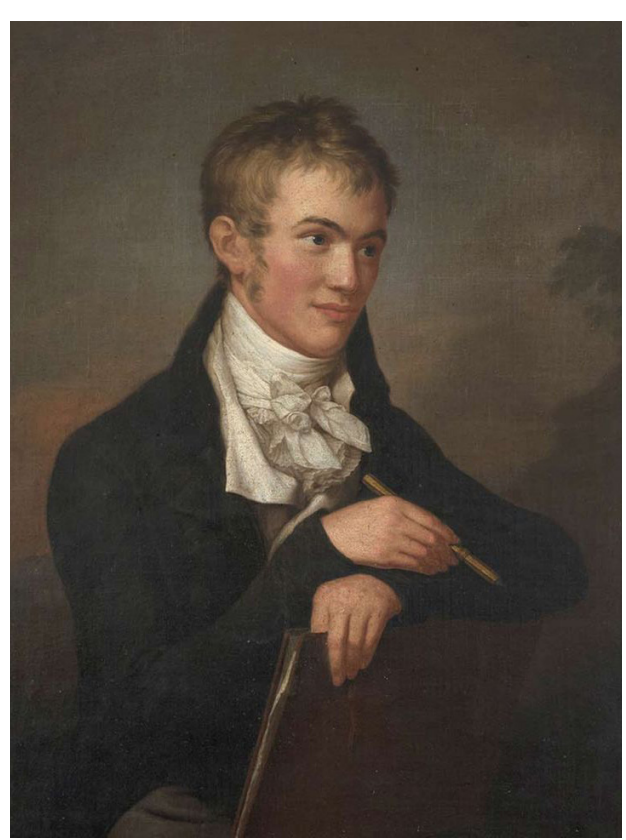

3 | Bildnis des Carl Friedrich von Rumohr, Gemäld von: Friedrich Carl Gröger, Ende 18. Jh. (๑ RumohrGesellschaft).

im September 1765 aus Warschau nach Dresden zurückkehrte. ${ }^{14}$ Grund dafür waren unter anderem zwei Todesfälle im Jahr 1763: zum einen der seines Patrons, des Grafen Brühl, für den er in Warschau und Wohla tätig war, zum anderen der des sächsisch-polnischen Monarchen, dessen Schlosskapelle er einst in Grodno erbaute. In jener Zeit der politischen Neuorientierung kehrte er nach Sachsen ins Oberbauamt zurück. In den ersten Jahren entstanden unter seiner Ägide um 1768 das Dresdner Gewandhaus aber auch das Schloss Reinhardtsgrimma - wahrscheinlich in beabsichtigter Nebentätigkeit als Landbaumeister im Oberbauamt Dippoldiswalde. Größere Aufgaben scheint er daneben nicht mehr ausgeführt zu haben. $\mathrm{Zu}$ seinem Werk bemerken Hentschel und May zusammenfassend:

»Die Entwürfe zu seinen Bauten sind sämtlich nicht nur architektonisch, sondern auch zeichnerisch ganz im Stile Knöffels gehalten, wobei höchstens eine
Art immer stärker werdende Nüchternheit zu bemerken ist. «15

Da nicht nur Knöbel, sondern auch zahlreiche andere sächsische Baumeister unter Johann Christoph Knöffel (1686-1752) ihr Handwerk erlernten und ausführten, zeichnet sich eine gemeinsame Formensprache ab. Die stilistischen Ähnlichkeiten des Schlosses von Reinhardtsgrimma zu Bauten wie dem kleineren Berreuther Haus, dem Gohliser Schlösschen aber auch zum vie größeren Schloss Hubertusburg zeigen, dass hier dem System eines quergelagerten Schlossbaus mit Mansarddach und barockem Dachreiter als gleichsam sächsischem "Erkennungszeichen « Rechnung getragen wurde. Zudem konstatiert die Forschung eine Nähe zum französischen Schlossbau, der in der zweiten Hälfte des 18. Jahrhunderts - gefördert durch international anerkannte Lehrer und Architekten wie JacquesFrançois Blondel (1705-1774) - eine commodité (d.h. eine funktionale und repräsentative Grundrisslösung) mit einem modern wirkenden Erscheinungsbild verband. Hierauf scheint es Lippold angekommen zu sein. Als einzige Zeichnung Knöbels hat sich lediglich der Grundriss des Kellergeschosses von Reinhardtsgrimma erhalten (vgl. Beitrag "Der Obstanbau", Abb. 7). ${ }^{16}$

Aus den Kirchenmatrikeln weiß man, dass Lippold 1773 die Hof- oder Schloßmühle neu errichten ließ, worauf 1779 die Brettoder Schneidemühle folgte. An der zu seinem Besitz gehörenden Mittelmühle, dem Erbgericht und der Schmiede scheint er keine Hand angelegt zu haben. Fast gleichzeitig brachten die in Folge des Bayrischen Erbfolgekriegs erfolgten Einquartierungen von Militärs im Winter 1778/79 in Reinardtsgrimma und Berreuth massive Vermögenseinbußen. ${ }^{17}$ Potenziert durch die zahlreichen Nachkommen, die nach dem od des Kammerrats im Jahr 1780 erbberechtigt waren, ließ sich Reinhardtsgrimma nicht halten, so dass es im Folgejahr für

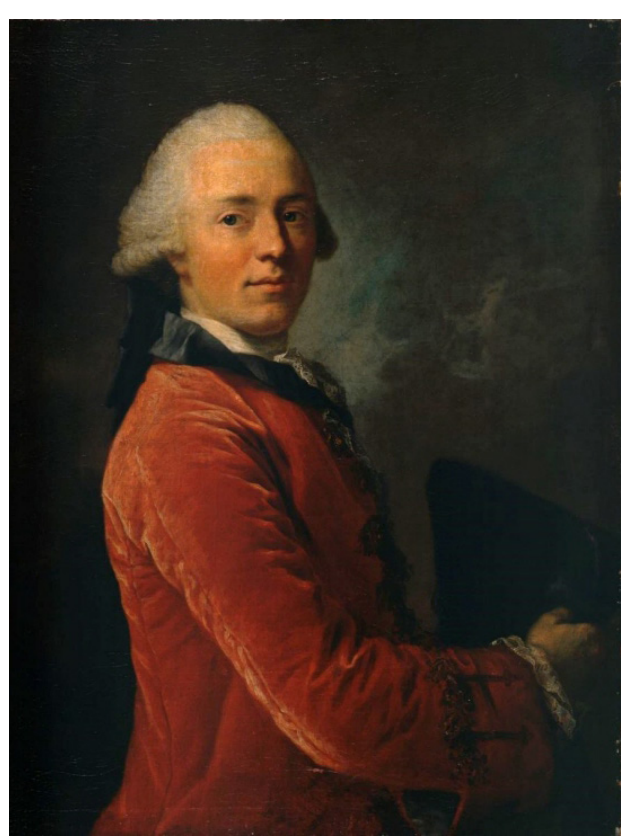

4 | Bildnis des Karl August Victor von Broitzem, Gemälde von Anton Graff, um 1775 (Aargauer Kunsthaus Aarau, Inv.-Nr. 835).

burgischen Landrat Henning von Rumohr benhufen bei Görlitz, sowie Röhrsdorf und (1722-1804) verkauft wurde. Insgesamt Lüttichau im Meißner Kreis. 1769 heiratete zeichneten elf Nachkommen bzw. Kinder, er die katholische Tochter des sardinischen die alle bürgerliche Namen trugen und Gesandtschaftssekretärs am sächsischen ebenso geheiratet hatten, den Kaufvertrag Hof, Marie Isabella Antonie Brunier de Claab..$^{18}$ Die Hoffnung des Erblassers mit dem refond (auch Clareford) (1748-1832), deren Gut auch ritterschaftliche, d.h. adlige Rechte Familie aus Savoyen stammte. 1785 wurde dauerhaft an seine Familie zu binden, wurde die überaus schöne Baronin von Anton damit nicht erfüllt. Graff gemalt (Abb. 5). Man muss davon ausgehen, dass Broitzem das Gut möglicher-

Da der altadlige Rumohr vor allem in der weise für seinen zweitgeborenen Sohn Curt Gegend um Lübeck begütert war (Trenthorst, Heinrich (gest. 1807) erwarb und sehr wahrGroß Steinrade, Bliestorf usw.), blieb er nur scheinlich deshalb kaum selbst in Reinhardbis 1785 in Reinhardtsgrimma und konzen- tsgrimma wohnte. Als führender Freimautrierte sich dann wieder auf seine norddeut- rer hatte Broitzem zwar Kontakte in Archischen Besitzungen. In jener Zeit wurde sein tekten- und Künstlerkreise, scheint diese Sohn, der später bekannte Gastrosoph und aber nicht für Reinhardtsgrimma genutzt zu Kunsthistoriker Karl Friedrich (1785-1843), haben. geboren (Abb. 3). und Gut dem Geheimen Kriegsrat Carl Vic- bel, Silber und Porzellan vom nachfolgentor August von Broitzem (1741-1812) (Abb. den Besitzer übernommen, so dass das 4) auf Ebersbach, Groß Krauscha und Sie- Schloss eine Grundausstattung behielt. ${ }^{19}$ 


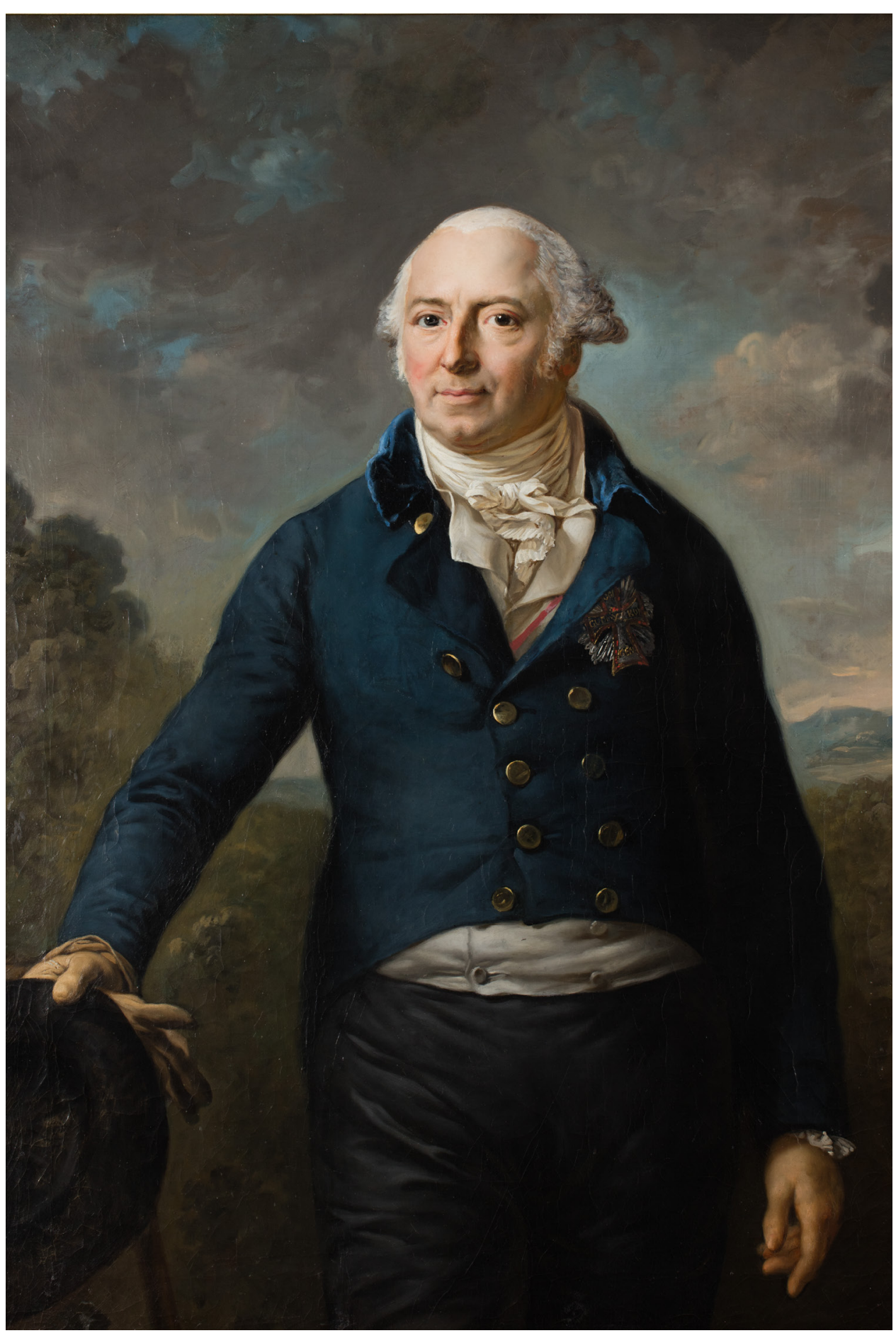

6 | Bildnis des Friedrich Ludwig Ernst Freiherr von Bülow, Gemälde von Anton Graff, 1810, Öl auf Leinwand, 123,5 x $95 \mathrm{~cm}$ (Kunstmuseum St.Gallen, Sturzeneggersche Gemäldesammlung, erworben von der Arnold BillwillerStiftung 1936).

\section{Die Ära Bülow}

Der nachfolgende Besitzer war de facto (nicht de jure!) der dänische Kammerherr Friedrich Ludwig Ernst von Bülow (17381811) (Abb. 6), der im Lüneburgischen die Güter Göddenstedt, Abbensen und Stellfelde, sowie die administrativ zu Pinneberg gehörende Herrschaft Herzhorn ${ }^{20}$ besaß, die ihm aus der Erbschaft seiner Frau Gräfin Anna Sophie Danneskiold-Laurvig (17451787) zugefallen war. ${ }^{21}$ Anna Sophie stammte aus einer wohlhabenden, einflussreichen $\mathrm{Fa}$ milie Dänemarks; ihr Vater, der Admira Christan Conrad (1723-1783) war väterlicherseits Urenkel Friedrichs III. von Dänemark und mütterlicherseits Neffe von Königin Anna Sophie von Dänemark, nach der seine Tochter benannt wurde. Folglich wurde diese auch Hofdame bei der dänischen Königin Karoline Mathilde. ${ }^{22}$ Bülow, dessen Karriere u.a. mit dem Großkreuz des Dannebrog Ordens belohnt wurde, erwarb sich als langjähriger außerordentlicher $\mathrm{Ge}$ sandter Dänemarks am sächsischen Hof, "mit Gnade seines Souverains und unseres geliebten Königs die Hochachtung aller, die ihn kennen lernten ${ }^{23}$.

Der spätere dänische Gesandte in Neape Christian Conrad (1768-1819) und sein Bruder Ernst Friedrich (1771-1834), Kinder Bülows, studierten von 1790 bis 1792 u. a. bei Georg Christoph Lichtenberg und Christian Gottlob Heyne in Göttingen, später reisten sie mit dem Troja-Forscher Jean Baptiste Le Chevalier (1752-1836) ein Jahr durch Europa. Die Familie war mit Friedrich von Matthisson ${ }^{24}$ und Klopstock befreundet, die Tochter Caroline Mathilde (1766-1843) mit Goethe bekannt. Die jüngste Tochter, Johanna Joachime Charlotte (Lotte) (17701837), heiratete 1796 den Hofmarschall Joseph Friedrich von Racknitz (1744-1818) (Abb. 7). ${ }^{25} 1799$ nahm er das ererbte Familiengut Ringethal vom Grafen Friedrich Car von Dallwitz-Königswartha und seiner Frau Johanna Margarethe, geb. von Racknitz, in Besitz. ${ }^{26} \mathrm{Da}$ es nicht nur zwei kunstvolle

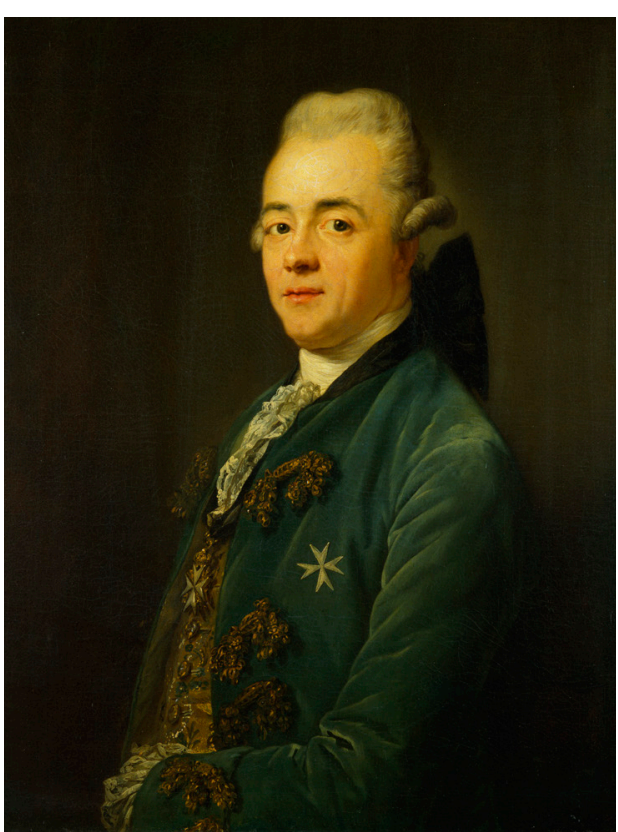

| Bildnis des Joseph Friedrich Freiherr von Racknitz Gemälde von Anton Graff, um 1776 (SKD, Gemäldegaerie Alte Meister, Inv.-Nr. Gal.-Nr. 2180 N)

Scherenschnitte von Blumen (Abb. 8a und b) ${ }^{27}$, sondern auch ein gestochenes Porträt nach einer Zeichnung Lotte von Bülows gegeben haben muss, ist sie möglicherweise auch diejenige Freundin, der Racknitz 1795 seine Briefe über die Kunst widmete. ${ }^{28}$ Mit seinen diversen Publikationen war er jemand, der in seiner Zeit Mode und Geschmack mitprägte.

Der Kauf Reinhardtsgrimmas im Jahr 1800 ür brutto 93.500 Taler erfolgte durch Bülows Tochter Johanna Joachime Charlotte, da er - wie er in seinem Testament von 1802 darlegte - als ausländischer Diplomat keinen Besitz in Sachsen kaufen durfte. Aus diesem Testament wird auch deutlich, dass die Söhne dereinst durch die Familiengüter versorgt würden, hingegen die Nutznießerinnen von Reinhardtsgrimma die drei Töchter, vor allem die beiden unverheirateten, Friederike und Caroline, sein sollten. Das Gut wurde von seinem und dem Erbe 

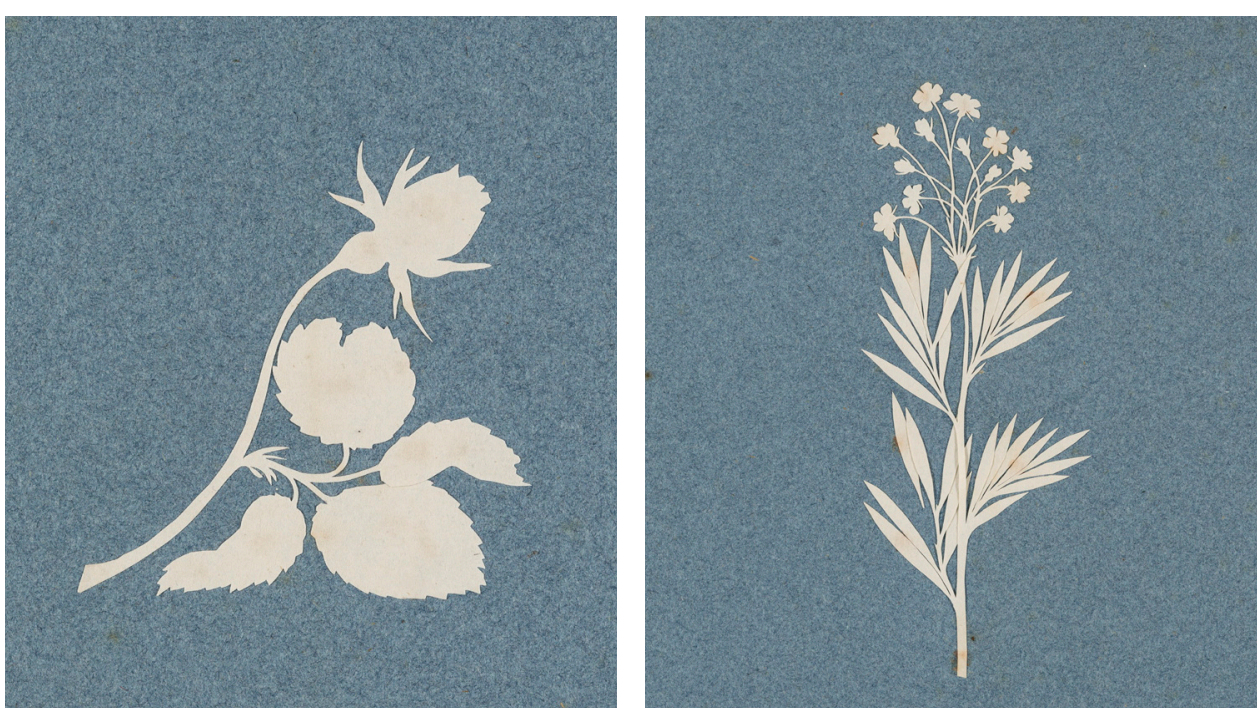

8a | Scherenschnitt einer Wildrose, erstellt von Char- $8 \mathrm{~b}$ | Scherenschnitt eines Blütenstengels, erstellt von lotte von Racknitz, Ende 18. Jh./1. Drittel 19. Jh. (SKD, Charlotte von Racknitz, Ende 18. Jh./1. Drittel 19. Jh. Kupferstich-Kabinett, Inv.-Nr. Ca 1988-6/102). theueren Ehefrau, deren zu frühzeitigen mahlin« der Familie annahm und die Zeit Verlust ich täglich betrauere ${ }^{29}$ erworben ihres Lebens, in der andere Töchter in der und sollte im Sinne der Familie in ein Allod Regel heirateten, dem Vater widmete. Be verwandelt werden. In seinem treusorgen- Aufsetzung des Testaments wurde deutlich, den letzten Willen wird ganz deutlich, dass dass sie wohl keine Nachkommenschaft er eine Lieblingstochter hat, zu deren Vorteil mehr zeugen würde und somit mehr oder das Testament ausfällt: minder auf sich allein gestellt war. ${ }^{32}$ Aus dem Jahr 1806 findet sich schließlich eine Schen"Dieses mein Ritterguth Reinhardts- kungsurkunde an Friederike Juliane in den grimma vermache ich also zuvörderst Akten. ${ }^{33}$ Über die beiden unverheirateten meiner herzlich geliebten Tochter Fre- Bülow-Schwestern schrieb der dänische derique Juliane Christiane, welcher ich Dichter Adam Oehlenschläger (1779-1850) hiermit für alle Freundschaft, zärtliche Die »Töchter traf ich später zuweilen be Liebe und Obsorge für mich und meinen Körner `s; sie waren sehr liebenswürdig und Hausstand den gerührtesten, herzlichsten geistreich; wir sprachen oft freundlich mit Dank unter tausendfältigen Segenwün- einander und eines Abends begleitete ich sie schen abstatte. «30 bis an ihre Haustüre « ${ }^{34}$

Über den Grund Bülows sich in Sachsen Um aber auch der ledigen Caroline nach sei- anzusiedeln, kann man nur spekulieren. nem Tod ein standesgemäßes Leben zu er- Hatte er doch am Hof Christians VII. von möglichen, garantierte er ihr eine Kammerjungfer und einen Diener. ${ }^{31}$

Dänemark erleben müssen, wie die persönliche Vorteilsnahme eines unfähigen Monarchen und fortlaufende Intrigen einen

Da Friederike Juliane das älteste Kind Bü- Machtverlust nicht etwa in einem Aufstand, lows war, darf man davon ausgehen, dass sie sondern in einer inneren Schwäche und eisich nach dem Tod der »vortrefflichen Ge- ner daraus resultierenden Übervorteilung durch andere Staaten enden ließen. Die Struensee-Affäre hatte 1772 zu seiner Entlassung und zur Übersiedlung Bülows nach Altona geführt, was lediglich durch eine jährliche Pension von 1.200 Reichstalern gemildert wurde. Als er 1793 rehabilitiert als Gesandter in den Staatsdienst zurückkehrte, muss sein Entschluss festgestanden haben, keine Finanzen mehr in Dänemark zu binden. ${ }^{35}$

Als Bülow das Gut kaufte, muss auch die Marmorskulptur Luigi Grossis (1754-1797) aufgestellt worden sein, die dieser in Erinnerung an die 1787 verstorbene Ehefrau Bülows anfertigte und 1791 in Carrara vollendete, als die Bülows noch in Altona lebten. ${ }^{36}$ Die qualitätvolle Skulptur findet sich heute nicht mehr im Park - ihr Verbleib ist bislang ungeklärt (vgl. Beitrag »Die Entwicklung der Gärten«).

Bülow investierte in den ersten Jahren in die Landwirtschaft, die Forsten, das Schloss und die Wirtschaftsgebäude. So wurde das überzählige »alte Schloss « auf dem Oberhof 1807 abgerissen und ein neues Brauhaus errichtet. ${ }^{37}$ Bei der Umgestaltung des Niederhofs scheint der Hofbaumeister Christian Friedrich Schuricht (1753-1832) eine Art Faktotum gewesen zu sein, das sich um die Inneneinrichtung, Brückengeländer, Zeichnungen, Organisation usw. zu kümmern und Bericht zu erstatten hatte. ${ }^{38}$ An Bülow schreibt er beispielsweise am 16. April 1802:

»Der Preiß der Tapeete steigt in Leipzig täglich höher, da die französischen Fabriquen sehr aufschlagen, ich bin bey verschiedenen en gros Händlern gewesen, wo solcher bloß in Stücken zu 8o Stab verkauft werden, allein der Stab oder 2 Ellen wird jetzo nicht anders als 31 Groschen verkauft, da man ihn in Dresden noch zu 14 Groschen die Elle haben kann.

Von Tapeten zu den weißen Panneaux in das Schlafzimmer habe ich in den Leipziger Niederlagen gleichfalls nichts gefunden, und mir haben in den Dresdner Fab- riquen jetzo noch beßere Desseins, jedoch erwarte ich von Leo eine Muster Charte in welcher verschiedene neue Leisten sind, und die ich Ihnen alsdann zuschicken werde. «39

Schuricht, dessen Höher-Bewerbung im Bauamt um den Posten des Oberlandbaumeisters 1799 zu keinem Erfolg führte, sah sich in jener Zeit zunehmend gezwungen, finanziell einträglichen Nebentätigkeiten nachzugehen, wozu zweifelsohne auch seine Aufgaben in Reinhardtsgrimma gehörten die er - wie er betonte - ohne Gehilfen zu bewältigen habe..$^{40}$ Der Kontakt dorthin ist möglicherweise durch Racknitz hergestell worden, mit dem er 1782 bereits nach Mannheim und Zweibrücken reiste, für den er 1796 den Titelkupfer für sein Buch »Darstellung des Geschmacks der vorzüglichsten Völker« lieferte und dem er 1798 durch einen Kupferstich seines Profils mit figürli-

chen Darstellungen huldigte..$^{41} 1799$ beschäftigte Racknitz ihn nochmals bei Umgestaltungen im kurfürstlichen Schloss in Dresden. Seine Zuarbeiten für ihn, aber auch für den deutschen Mentor des Landschafsgartens Hirschfeld und dessen Nachfolger Wilhelm Gottlieb Becker (»Das Seifersdorfer Tal«, 1792) sowie für »Grohmanns Ideenmagazin« zeichneten ihn zudem als einen $\mathrm{Ar}$ chitekten aus, der im besten Sinne auch ein Protagonist der »Landschaftskunst" wa (vgl. Beitrag »Die Entwicklung der Gärten $\ll)$.

Kurz vor Bülows Tod tauchen die Buschhausschänke an der Landstraße nach Hausdorf, eine neue Scheune und das Brauhaus mit »herrschaftlicher Stube» in den Bauakten auf. ${ }^{42}$ Die Planung der qualitätvoll im klassizistischen Stil ausgestalteten Buschhousschänke wird dem Hofarchitekten Gottob Friedrich Thormeyer (1775-1842) zugeschrieben. ${ }^{43}$ Die bislang in Fachkreisen vorherrschende Meinung, dass das Schießhaus vis-à-vis der Schänke zur selben Zeit wie diese erbaut worden sei, konnte im Zuge der 
sich hierbei vielmehr um zwei Bauabschnitte stark und fest gegen alle traurigen Welthän- das Schießhaus wurde erst nach dem Able- del « ${ }^{49}$ macht. In den Akten findet sich 1814 ben von Bülows errichtet. ${ }^{45}$ Bemerkenswert wieder ein Verweis auf Friederike Juliane, sind zwei vermutlich von dem Hofbildhauer als sie Generalleutnant Carl Adolf von CarFerdinand Pettrich (1798-1872) angefertigte lowitz (1771-1837), mittels eines an ihn geGiebelreliefs, welche die beiden Gebäude richteten Schreibens Kaiser Alexanders von straßenseitig zieren (die Tür der Buschhaus- Russland um Hilfe für ihre Gemeinde bat..$^{50}$ schänke wird vom Relief eines ruhenden Wanderers, die Tür des Schießhauses von ei- „Hatte einst der jüngste Sohn die Verantnem Tiroler Jäger bekrönt). ${ }^{46}$ Ihre Bildspra- wortung meiner Forsten auf Reinhardtsche zeigt an, dass sich »bürgerlich-natio- grimma zu meiner völligen Zufriedenheit nale« Geisteshaltungen - im Sinne des auf- mit allem Fleiß unterzogen«, wie Bülow im strebenden bürgerlichen Politikbewusst- Testament schrieb, so empfahl 1802 Bülows seins nach den Befreiungskriegen - auch Halbbruder ${ }^{51}$, der Erbmarschall Friedrich verstärkt in Reinhardtsgrimma manifestier- August Otto von Behr auf Stellichte (1750ten (vgl. Beitrag »Zwischen Physiokratie 1807), seinen jungen Förster-Eleven Georg und Landschaftsverschönerung «). Unter der Konrad Ruschenbusch (1785-1866) nach Ägide von Bülows wurden zudem zwei wei- Reinhardtsgrimma. Dieser hatte nicht nur in tere anspruchsvolle Bauwerke projektiert: In den jagdlich ausgerichteten Wäldern von den Akten findet sich der von einem nicht Stellichte gelernt, sondern Behr war auch näher bezeichneten Hofarchitekten (viel- bereits Taufpate bei dessen jüngeren Bruder leicht Schuricht oder Johann August Giesel) Friedrich August (1790), der wiederum um um 1804 verfertigte Kostenvoranschlag zu 1825 Verwalter auf dem bülowschen Gut einem Mausoleum, zu dem es auch Zeich- Göddenstedt wurde. Dieser Bruder heiratete nungen gegeben haben muss. Nach den bis- 1811 Christiane Louise Rheb (1790-1873), die herigen Forschungen bleibt unklar, welches uneheliche, aber akzeptierte Tochter ChrisGebäude hiermit gemeint sein soll, es han- tian August Ludwig Adolph von Behrs delt sich sehr wahrscheinlich um eine nicht (1755-1815), der mit seinem Bruder Albrecht realisierte Planung für von Bülow. ${ }^{47}$ Das Burchard Carl Stellichte 1807 erbte.

gleichzeitig auf einer Anhöhe im Schloss-

park errichtete klassizistische Badehaus, für In die Zeit Bülows fällt nicht nur die »Origidessen Entwurf Schuricht verantwortlich nal Charte vom Rittergut Reinhardts zeichnete, besitzt - in künstlerischer und grimma (1808/o9), die den Zustand des gefunktionaler Hinsicht - Singularität in Sach- samten Guts wiedergibt, sondern auch die sen (vgl. Beitrag »Die Entwicklung der Gär- kolorierte Forstkarte von 1807.52 Auf beide ten $«)$. wird an anderer Stelle noch zurückgekommen (vgl. Beitrag "Zwischen Physiokratie Spätestens ab 1807 muss Friederike Juliane und Landschaftsverschönerung«). die Geschäfte der Gutsherrschaft Reinhardtsgrimma in ihren Händen gehalten ha- Reinhardtsgrimma unter Ruschenbusch ben, da es zwischen ihr und dem Pächter Johann Andreas Walther zu einer gerichtli- Die Heirat Friederike Juliane von Bülows chen Auseinandersetzung kam, die mit der mit dem Förster und Verwalter Georg KonRückgabe der Pacht 1810/11 endete..$^{48} \quad$ rad Ruschenbusch (Abb. 9) war aufgrund Nach dem Tod des Barons erfolgte 1812 ein des Alters - und Standesunterschieds unge"Erbvergleich" der Kinder, der jedoch güt- wöhnlich, lässt sich jedoch auf das oben belich im Sinne des Erblassers von statten ging, schriebene Beziehungsgeflecht zurückfühmahnte er doch in seinem Testament, »daß ren. das Zusammenhalten einer Familie sie nur
Laut Überlieferung soll Ruschenbusch bereits 1820 Verwalter des Guts Reinhardtsgrimma gewesen sein. 1830 wurde als er als Mitglied in der Ökonomischen Societät Leipzig geführt, in der sich Landeigentümer, Interessierte, Forscher und Staatsbeamte zusammengefunden hatten, um die Agrarund Volkswirtschaft zu verbessern. Dies fällt in eine Zeit, in der sich Ruschenbusch zusehends um die Gutswirtschaft gekümmert haben muss. Der Bau des Erbgerichts 1830, aber auch der Neubau der 1837 abgebrannten Schäferei durch den Röhrsdorfer Maurermeister Johann Gottlieb Adam lagen ihm dabei sehr am Herzen. Letzteres ein »Gebäude, wie ein zweites in Sachsen nicht leicht zu finden sein dürfte « ${ }^{53}$, wie man bei Poenicke lesen kann (vgl. Beitrag »Zwischen Physiokratie und Landschaftsverschönerung ", Abb. 11). Auch wenn die Schafzucht nicht mehr so populär war wie im ausgehenden 18. Jahrhundert und der etwa 700 Tiere zählende Stamm in Reinhardtsgrimma kein besonderer war, dürfte Georg Conrad durch seine Lehrzeit in der Lüneburger Heide die Schafbeweidung geschätzt haben. Ferner ließ der neue Gutsherr 1847 am Bach ein neues Wirtschaftsgebäude durch den Baumeister K. G. Gäbel (gest. 1868) aus Kreischa errichten, ${ }^{54} 1853$ folgte an einem nicht genauer bezeichneten Seitenflügel der Anbau eines Eiskellers (Abb. 10). ${ }^{55}$ Pastor Rudolf Bernhard Hoffmann schrieb 1886 rückblickend: "Seit 1843 hat sich das Rittergut sehr vergrößert und verschönert. Die Felder stehen in hoher Kultur. $\aleph^{56}$

1830 setzte die Gutsherrin, da sie sich durch »die Güte und Großmuth « ihres Vaters dazu aufgefordert sah, ein Testament zu Gunsten ihres Gatten, für ihren "zeitherigen Freund $\wedge^{57}$, auf, wobei sie vor allem den Verbleib allen beweglichen Mobiliars regelte, das sie einst ihren Geschwistern abkaufen musste..$^{8} 1831$ erwarb Ruschenbusch schließlich für 90.000 Taler das Gut Reinhardtsgrimma von seiner Frau, da man seine adoptierten Neffen Georg Conrad II. (gest. maliger Treppenhausanbau an der Kirche 1897) als möglichen Erben sah und dieser bereits belegt war, wurde 1865 der Gutsfried-

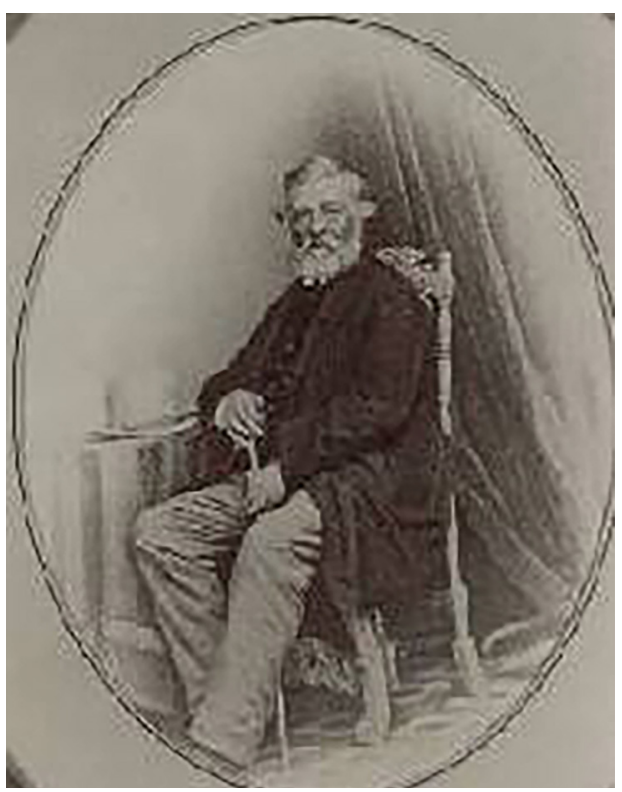

9 | Fotografie von Georg Konrad Ruschenbusch, undatiert (Ahnenforschung in Preussen \& Lippe, http:// www.arendi.de/_Ruschenbusch/Generation\%20\%208.

womöglich nur durch den Verkauf hätte begünstigt werden können. 1832 starb sie, so dass er mit der Pfarrerstochter Anna Marie Schubert die zweite und - nach deren frühem Tod - eine dritte Ehe mit Ernestine Auguste von Brandenstein (1816-1890) einging die im Unterschied zu ihren Schwestern, die n die Familien Bünau und Friesen einheirateten, ihren adligen Status damit aufgab. Sie brachte 1836 die Tochter Friederike Conradine (gest. 1910), die nach Ruschenbuschs erster Frau und ihm selbst benannt wurde, sowie den früh verstorbenen Sohn Carl Gotthold zu Welt. Unter dem besagten Kaufvertrag von 1831 findet sich als Zeuge (»Special Curator «) übrigens ihr Vater, der sächsische Oberst Leutnant der Kavallerie Ernst Friedrich von Brandenstein (1775-1856 Reinhardtsgrimma), der dort bereits zu wohnen schien. ${ }^{59}$ 


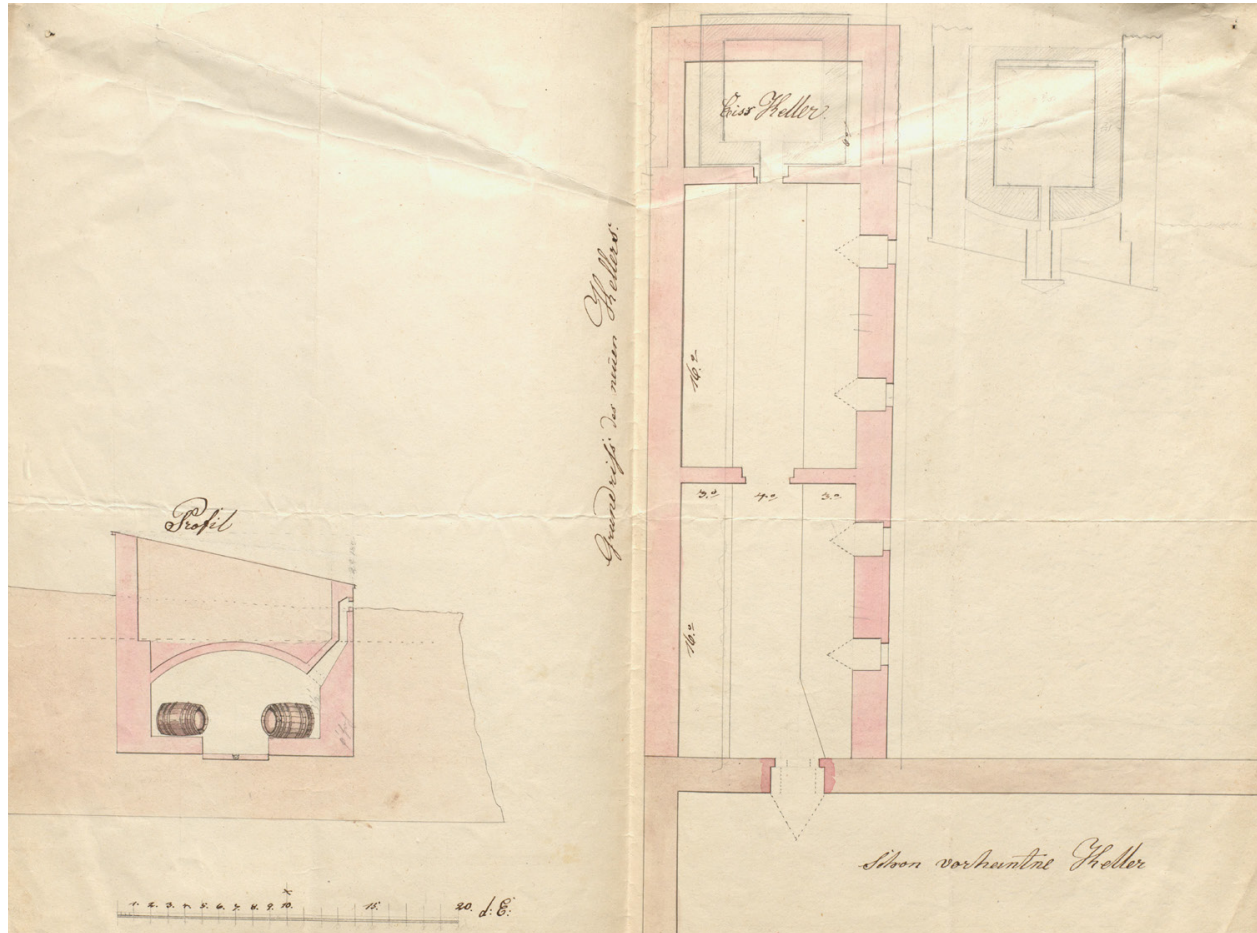

10 | Grundriss und Profil des neuen Kellers (für Fässerlagerung), Federzeichnung farbig laviert (Ausschnitt), 1853 (SächsHStA, 10505, Nr. 509, Drei Skizzen zur baulichen Veränderung am Schloss Reinhardtsgrimma ohne Datum).

hof eingerichtet, auf dem Ruschenbusch ein zen 1833 - Dresden 1907), der einer Familie Jahr später beerdigt wurde. Die heute noch von führenden Militärs entstammte (Abb. bestehende Anlage wurde auch von der ab 11); sein Vater war Stadtkommandant von 1908 in Reinhardtsgrimma ansässigen Fami- Dresden. Wie auch seine Frau, hatte Aster lie von Senfft unterhalten und benutzt, wo- eine adlige Mutter, Henriette Emilie von bei die Pflege in den Händen des Gutsgärt- Weißenbach. Ein Zweig der Asters - der ners bzw. des Pächters der Schlossgärtnerei Onkel Ernst Ludwig - wurde sogar geadelt. lag. ${ }^{61}$ Mit Ruschenbuschs Tod wurde die

nach ihm und seinem Sohn benannte $>$ Ge- Auf Schloss Reinhardtsgrimma muss man org Conrad und Gotthold Ruschenbusch damals - folgt man einem späteren Inventar Stiftung zur Versorgung verarmter Gutsar- - Bildung und Unterhaltung gegenüber aufbeiter ins Leben gerufen, da nunmehr das geschlossen gewesen sein: Es finden sich Ehepaar Aster Gutseigentümer wurde und nicht nur etliche Musikinstrumente sondern die Erinnerung an die Verstorbenen damit auch »ausgestopfte Thiere und Vögel, Käfer" wachhalten wollte. ${ }^{62}$

\section{Das Ehepaar Aster} sammlung, die durch eine "Steinsammlung mit Schrank« erweitert wurde und an die Kollektionen erinnert die durch Persönlich-

Im Jahr 1859 heiratete die Tochter und ein- keiten wie Johann Wolfgang von Goethe in zige Ruschenbusch-Erbin Friederike Con- der ersten Hälfte des 19. Jahrhunderts popuradine den Major Ludwig Emil Aster (Wur- lär wurden. ${ }^{6}$
Es ist nicht unwahrscheinlich, dass sich Aster nach dem aktiven Militärdienst mit umso größerer Freude Reinhardtsgrimma zuwandte, da er zwischen 1874 bis 1882 auch als Direktor der "Ökonomischen Gesellschaft im Königreich Sachsen « amtete. Dort scheint er nicht nur eine segensreiche Tätigkeit entfaltet zu haben, sondern machte sich auch als Kaninchenzüchter einen Namen. ${ }^{6}$ Dieses Interesse an der Landwirtschaft zeichnete ihn aber schon vorher aus, das zumindest legt das Gutsarchiv nahe: So ist ab 1861 eine moderne landwirtschaftliche Buchführung feststellbar, woraufhin wahrscheinlich 1865 ein Inventar angelegt und 1874/75 dieses noch einmal überholt wurde; 1868 schaffte man sich eine Dreschmaschine von C. Böttger aus Schlottwitz an und konzipierte Neubauten. So etwa ab 1867 den Anbau eines Schweinestalls an das Kuhstallgebäude ${ }^{65}$, die Abtragung des vorhandenen Schweinestalls sowie die Errichtung eines Futterschuppens und eines Hühnerstalles, die Erweiterung des Ochsenstalles, die Einrichtung eines Stalles für Gastpferde usw. Die Verantwortlichkeiten lagen in den Händen des Baumeisters Otto Röllig, der auch in den nächsten Jahrzehnten immer wieder tätig wurde. Zudem scheint man die schwächelnde Brennerei, die 1842 noch Korn- und Kartoffelschnaps sowie Kirschbranntwein und Bitter herstellte, den man auch den Gutsarbeitern zum Erntefest spendierte, um 1874 neu einrichten zu wollen. ${ }^{66}$

Die Tätigkeit Asters in der »Okonomischen Gesellschaft « ist vermutlich Auslöser fü diese Innovationen gewesen, kümmerte man sich doch dort um die Einführung neuer Technologien und Methoden zur Steigerung der landwirtschaftlichen Produktion. Das Flurbuch, das in den Jahren 1874/75 begonnen und fortgeführt wurde, mag als eine dieser Anregungen gelten, da es die Bestandteile einer hochspezialisierten Gutsführung und -erfassung zusammenführt. ${ }^{6}$ Das Flurbuch, das etliche Karten enthält, gibt dabei detaillierte Angaben zu jeglichen Ausgaben und Einnahmen, Viehbeständen,

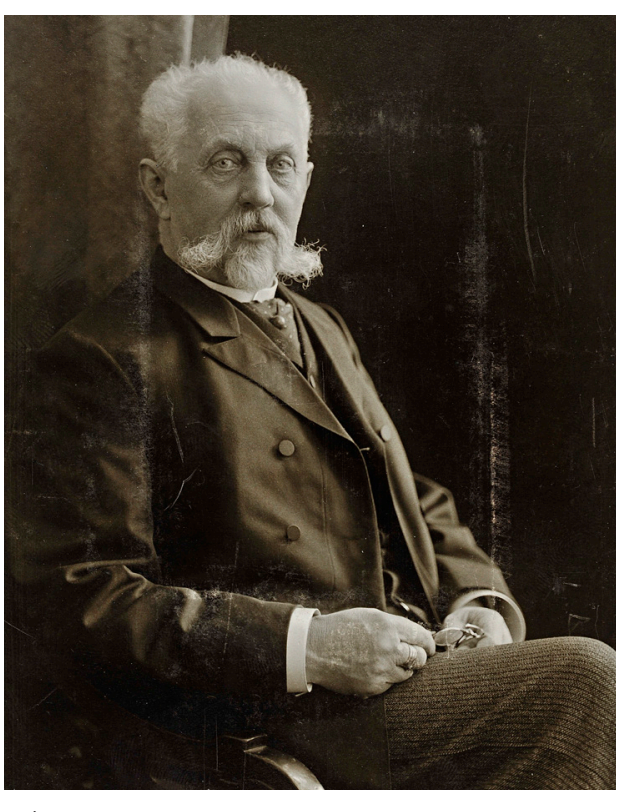

11 | Fotografie des Majors Ludwig Emil Aster, undatier igital.de/index.php?t=objekt\&oges=603900)

Feldbestellung, Düngung, Erträgen, Forstund Obstbaumbeständen, Arbeitseinsätzen, Planungen usw. Diese Art der Buchführung ist gleichsam ein Meisterwerk der Agrarökonomie. Das Gutsarchiv selbst kann trotz Lücken den Nachweis liefern, dass man in modifizierter Form bis weit ins 20. Jahrhunder diesem Flurbuch folgte. Es ist insofern eine

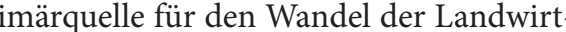
schaft.

Warum Reinhardtsgrimma durch die Asters verkauft wurde, bleibt im Dunkeln. Die Inventare zeigen jedoch, dass man zu Zeiten des Verkaufs einen sehr bescheidenen Haushalt führte. Der versicherungsbedingt aufgeführte und vermeintliche "Luxus-Ausbau ${ }^{6}$ des Schlosses ist deshalb auch nicht richtig nachvollziehbar. ${ }^{69}$ Der 1880 erfolgte Verkau der kurz zuvor sanierten Gaststätte im Dorf an Ernst Robert Jungnickel ist wahrscheinich schon ein Beleg dafür, dass die finanziellen Mittel knapp wurden. ${ }^{70}$ Hierfür sind möglicherweise zwei Umstände verantwort- 
zehntelanger Anpassungsprozess verschie- halten haben, die dessen Rechte und Pflichdenster Rechtsformen voraus, mit dem Ziel ten festhalten. ${ }^{74}$ Die Paragraphen lassen die bisherigen Abhängigkeitsverhältnisse Spielräume zu, die oftmals Grund für Streizwischen Grundherren und Untertanen zu- tigkeiten darstellten, da Vorgänge nicht im gunsten von Staatlichkeit und Kommunal- Vorfeld abgesprochen, sondern im Nachwesen aufzuheben. Dieser Prozess dauerte gang gerichtlich ausgehandelt wurden. Im in Reinhardtsgrimma bis in die Weimarer Unterschied zu diesen historisch häufig beRepublik an, als die eigenständigen Dorfge- legten Auseinandersetzungen, die nicht selmeinschaften (Ober-, Niederhof und Dorf) ten das Aufeinanderprallen herrschaftlicher zu einer politischen Gemeinde zusammen- Vorstellungen mit wirtschaftlichen Realitäwuchsen. Welche Mechanismen im Detail ten widerspiegeln, haben sich jedoch alle Eiauch in Reinhardtsgrimma wirkten, müsste gentümer Reinhardtsgrimmas im 19. Jahrnoch untersucht werden.

Neben fehlenden Einnahmen lieferten mög-

licherweise aber auch Fehlinvestitionen ei- Neben den festangestellten Bediensteten wie nen Grund für den Verkauf. Bei allen Ambi- Förster, Gärtner, Schafmeister, Brenner tionen, die Aster gegenüber der Landwirt- Schirrmeister und der Wirtschafterin, tauschaft hegte, darf man nicht vergessen, dass chen zahlreiche Knechte auf, die zeitweise er weder Erfahrung hatte, noch ein Spezia- durch Tagelöhner (teilweise bis zu 30 Mänlist war. Im Jahr der Verkaufsverhandlungen ner und Frauen) Hilfe bekamen. Zu ihren gab er seinen Posten bei der "Ökonomi- Aufgaben zählten beispielsweise Fuhr schen Gesellschaft « auf. Aufschlussreich dienste verrichten, Heu machen, Hecken mag auch die Tatsache sein, dass beim Ver- schneiden (es gab etwa zwei Kilometer dakauf des Ritterguts 1883 für 750.000 Mark an von), Eiskeller säubern und einräumen, Futden Kaufmann Nitzsche lediglich Asters ter herstellen, Ernte einbringen, Holz haFrau als Verkäuferin auftrat, da ihm das Gut cken usw. Die getöteten Maulwürfe, von dewahrscheinlich nie gehört hatte.

Der landwirtschaftliche Wandel auf dem Rittergut Reinhardtsgrimma im ausgehenden 19. Jahrhundert Die Gutswirtschaft umfasste im 19. Jahrhun- sesteine vom Feld zu räumen. ${ }^{76} \mathrm{Zu}$ Beginn dert ungefähr 245 Hektar Wiesen- und des 20. Jahrhunderts wurden diese AufgaFeldflur sowie 225 Hektar Wald, zusätzlich ben durch ruthenische, d.h. westukrainische einige Teiche, zwei Gasthöfe und Mühlen, Leiharbeiter übernommen, die vor allem in womit sie zu den größeren Gütern im Um- der Erntezeit durch Agenturen vermittelt kreis zählte. ${ }^{72}$ Einnahmen wurden durch wurden. ${ }^{77}$

Verkäufe landwirtschaftlicher Produkte oder von Holz, Heu, Obst, Spirituosen sowie In den Unterlagen findet sich an zahlreichen durch Pachten, Vermietungen und geringfü- Stellen der Hinweis, dass Lesesteine geschlagig auch mittels der Fischerei und durch gen wurden (»Steinklopfen«), was darauf kleine Abverkäufe in der Gärtnerei oder hindeutet, dass man diese als Wegeunterbau auch von Wildbret erwirtschaftet. ${ }^{73}$ In der verwendete. Da die Instandhaltung der StraRegel wurde der Gutsbetrieb von einem ßen und Wege aber auch der wasserbauliVerwalter (zuweilen auch Pächter oder »Ins- chen Anlagen (Brücken, Ufer, Schleusen) zu pector « genannt) geführt, wobei sich aus der einem erheblichen Teil dem Rittergut oblag, Zeit der Tettaus und Asters zwei Verträge er- finden sich zahlreiche Abrechnungen, die im ausgehenden 19. Jahrhundert einen heute noch an etlichen Stellen sichtbaren Wegebau belegen. Die befestigten Oberflächen ermöglichten in der Feldmark und im Wald einen von Wetterunbill weitgehend ungehinderten Transport. Es waren nicht nur mangelnde Kenntnisse im Chaussee- und Wegebau, sondern auch fehlende Ressourcen und eine durch Partikularinteressen gesteuerte Gesetzgebung, die zuvor eine solche Entwicklung behindert hatten. Eine der letzten Auseinandersetzungen über »Wegegerechtigkeiten « betrifft die gemeinschaftlich geregelte Unterhaltspflicht der um 1900 installierten elektrischen Ortsbeleuchtung.

Die Bücher geben darüber hinaus einen detaillierten Überblick über den Viehbestand, der teilweise bis hin zu Kaufrechnungen und Abstammungslisten belegbar ist. Dabei wird deutlich, dass man mehr und mehr von ei ner Weide- zu einer Stallhaltung um schwenkte. Die effiziente Aufforstung führte beispielsweise dazu, dass der Schafbestand von etwa 450 Tieren im Jahr 1865 auf 290 im Jahr 1874 sank..$^{78}$ Es standen den Tieren einfach weniger Gutsflächen zur Beweidung offen, wie auch das Begehen der Gemeindeflächen keine Selbstverständlichkeit mehr zu sein schien. Durch eine zunehmende Technisierung wurden allmählich auch die Ochsen (in den Akten als »Zugvieh« bezeichnet) abgeschafft, so dass man von den ursprünglich fünf Ochsenknechten um 1900 nur noch zwei behielt, bis auch diese schließlich ganz aus den Akten verschwinden. Die Verbesserung der Zufütterung aber auch die Ertragssteigerungen, die sich auf den heimischen Feldern durch den Anbau von Viehfutter (z.B. Kartoffeln) aber auch durch die Gabe ausreichenden Grünfutters erreichen ließen, wirkten sich hingegen förderlich für den Viehbestand - vor allem Milchkühe und Schweine - aus. Waren es um 1865 etwa 50 Kühe und 12 Schweine mit 33 Ferkeln, so wurden 1907 schon 72 Melkkühe, »66 Kalben und Kälber" sowie 66 Schweine gezählt. ${ }^{79}$

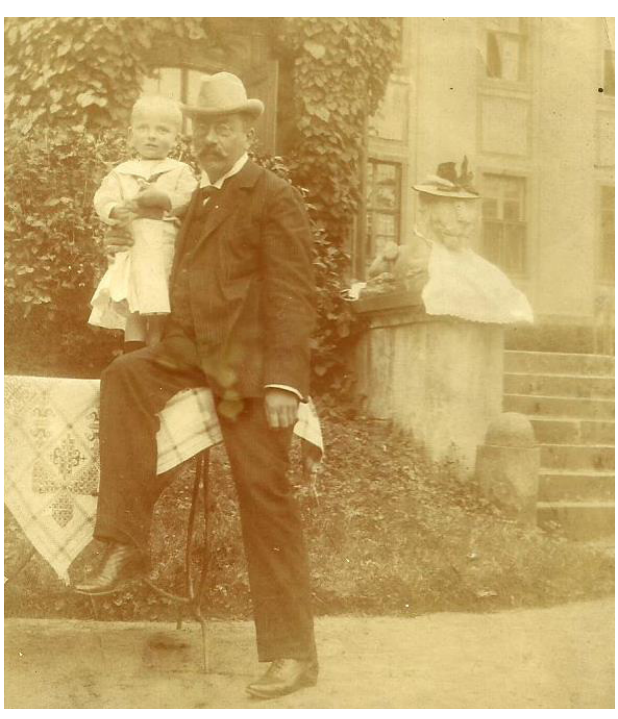

2 | Fotografie von Johann Maximilian Nitzsche mi seinem Sohn Reinhardt-Wilhelm, um 1895/1900 (Privatarchiv Johann Georg Nitzsche, Frankfurt a.M.).

Festzuhalten ist, dass das Gutsarchiv Reinhardtsgrimma in seiner Überlieferung einen eindeutigen Schwerpunkt im Bereich der Landwirtschaftsgeschichte birgt. Sie wird in dieser Publikation, insofern sie mit dem Gartenbau verwandt ist, behandelt, wobei die angedeutete wissenschaftliche Auswerung noch erfolgen muss.

\section{Die Kaufmannsfamilie Nitzsche}

Der Leipziger Kaufmann Christoph Georg Conrad Nitzsche (1817-1867) besaß ab 1863 das Gohliser Schlösschen, das baulich gewisse Parallelen zu Reinhardtsgrimma zeigt, wenngleich es auch älter ist. Sein dort geborener Sohn, Johann Maximilian Nitzsche (1857-1904) war bereits im Alter von 25 Jahren der Käufer der umfangreichen Liegenschaft Reinhardtsgrimma (Abb. 12). Erst 1892 heiratete er Helene Caroline Auguste (geb. 1869), Tochter des schwarzburg-rudolstädtischen Staatsministers Wilhelm Friedrich von Starck (1835-1913). Über deren Begrüßung in Reinhardtsgrimma liest man: 
»Frau Nitzsche hielt am 22. Mai hier ihren aus Reinhardtsgrimma taucht immer wieder Einzug. Dafür war am unteren Eingang auf, wenn es beispielsweise um den Bau des der Bezirksstraße ins Dorf eine Ehren- "Akkumulatorenhauses und die elektrische pforte errichtet. Vorreiter eines Festzuges Anlage« (1899), um die Renovierung der waren dem Paar entgegengeritten, Ver- Brauerei auf dem Oberhof (1900), die Vereine und Schulkinder gingen ihm bis zur größerung des Pferde- und des Kuhstalls, ${ }^{82}$ Brettmühle entgegen, wo zwei Schulmäd- einen Scheunenneubau (1889) oder den chen der jungen Frau einen Blumen- neuen Eiskeller (1890) geht. ${ }^{82}$ Die modernen strauß überreichten. An der Ehrenpforte Zeiten wirkten sich also auch auf die Landsang der Gesangverein ein Willkom- wirtschaft aus: 1891 wurde eine Feldscheune menslied und Gemeindevorstand Hoff- gebaut, zu der sich 1892 eine Lokomobile gemann sprach einige Begrüßungsworte. sellte, d.h. eine mobile Dampfmaschine, die Dann schloß sich der Gemeinderat dem man schon 1888 probeweise gemietet zu haZuge an, der sich nun nach den Klängen ben schien; gleichzeitig experimentierte der Frauendorfer Musikkapelle nach dem man mit Serradella (Ornithopus sativus) als Schloßhofe in Bewegung setzte. Dort hat- Grünfutterpflanze. ${ }^{83}$ Zwischen 1899 bis 1905 ten sich zu beiden Seiten Beamte und Ar- wurde schrittweise auch die Elektrizität einbeiter des Rittergutes aufgestellt. Nach- geführt.

dem Pastor Hoffmann an der Schloß-

treppe eine Begrüßungsansprache gehal- Modernisierungen lassen sich unter Nitzten hatte, zog der Festzug nach dem sche aber nicht nur im Bereich der LandErbgericht ab. Am Abend veranstalteten wirtschaft, sondern auch im Garten und am die Schulkinder einen Umzug mit bunten Schloss belegen: In den Akten findet sich Laternen von der Schule nach dem beispielsweise ein Gartenplan des königliSchloßhof. $\ll^{80}$ chen Hofgärtners Max Bertram (1849-1914) auf den im Folgenden noch detaillierter ein-

Vier Kinder wurden dem Paar in Rein- gegangen wird. (vgl. Beitrag "Die Entwickhardtsgrimma geboren, bekannt ist die 1893 lung der Gärten«) Darüber hinaus gibt es geborene Charlotte Melanie Minna (1893- eine Zeichnung (Abb. 13), welche die Maß1984), die 1914 Burkhardt Karl Ernst Rabe nahmen an den Schornsteinen im Schloss von Pappenheim (1879-1945) heiratete, zeigt und durch keinen geringeren als den Oberleutnant der kaiserlichen Schutztruppe Königlichen Baurat und Dresdner Professor in Deutsch-Ostafrika.

Constantin Lipsius (1832-1894) unterzeichnet wurde, der zeitgleich mit dem renomDer Kaufvertrag wurde erst am 2. Februar mierten Neubauprojekt der Akademie in
1883 unterzeichnet, doch scheint es unter Dresden beschäftigt war. Mit den Umbauten Nitzsche bereits Ende 1882 zu einigen Verän- in den Schlössern Püchau, Wetzelstein und derungen gekommen zu sein. Dies verwun- Klein Zschocher hatte er zudem gezeigt, dert nicht, schrieb doch Pfarrer Hofmann dass ihm auch Modernisierungen nicht 1886 über die Ambitionen des Gutsherren: fremd waren. Man muss davon ausgehen, "Die Ökonomie ist noch verpachtet, doch dass Lipsius hier nicht allein wegen der Esgedenkt der jetzige Herr Besitzer dieselbe sen sondern auch wegen anderer baulicher d.r. Juli 1887 selbst zu übernehmen. $\aleph^{81} \mathrm{Ob}$ - Veränderungen angefragt wurde, die jedoch wohl er keine landwirtschaftliche Vorprä- im Gutsarchiv keinen Niederschlag gefungung gehabt zu haben scheint, investierte er den haben.

in den Gutsbetrieb und war Mitglied im

»Landwirtschaftlichen Haupt-Verein Sach- Diese Umstände mögen zeigen, mit welchen sen«. Der bereits auf dem Gut tätige »Bau- Ambitionen Nitzsche das Rittergut Reinmeister und Steinbruchbesitzer« Otto Röllig hardtsgrimma zu führen trachtete. Durch

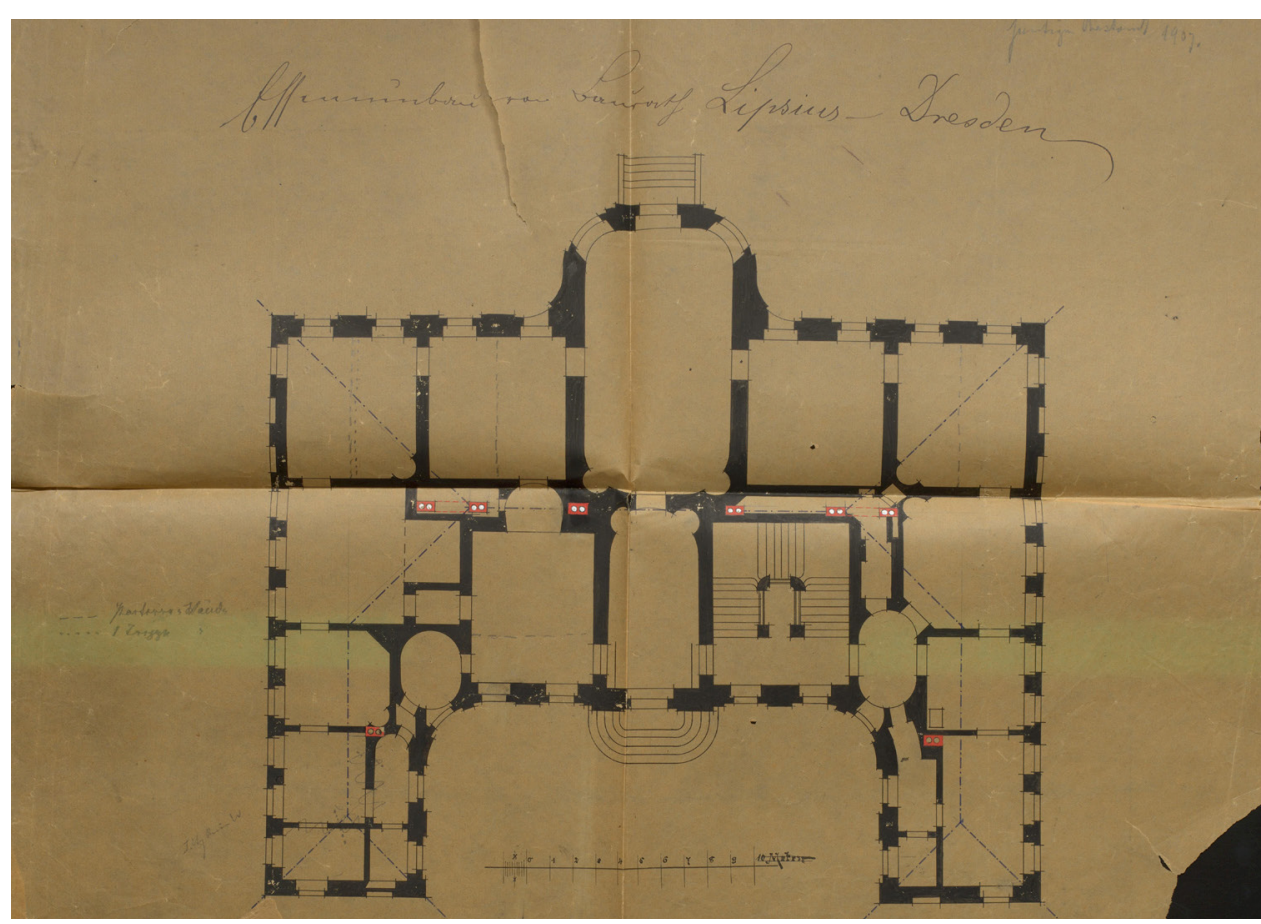

13 | Grundriss von Schloss Reinhardtsgrimma »Essenumbau von Baurath Lipsius - Dresden«, »fertiger Bestand 1907《 (SächsHStA, 10505, Nr. 409, Pläne des Schlosses Reinhardtsgrimma 1907).

seinen frühen Tod und aufgrund der Min- lem Anbau sowie zwei Wirtschaftshöfe, die derjährigkeit der Kinder wurde das Gut Schloss- und die verpachtete Brettmühle schließlich am 1. August 1907 verkauft, was mit Elektrizitätswerk, die verpachtete Bävon 1907 bis 1908 zu zähen Verhandlungen ckerei, der Oberhof mit ehemaliger Brauerei mit den Neueigentümern, der Familie Senfft und Mietwohnungen, die Buschhäuser, die von Pilsach, führte. Man rechnete 1.013.00o Brennerei (»17358 1 Kontingent«), die GärtMark zusammen, wobei das Schloss mit le- nerei, Obstplantagen sowie der Gutshof mit diglich 50.000 Mark zu Buche schlagen allem Inventar und Vieh. ${ }^{84}$

sollte, weil es erheblichen Sanierungsbedarf

gegeben haben muss. Die Witwe jedoch kam Tatsache ist, dass beide Seiten so auseinanauf 1.400.00o Mark, da zahlreiche Investiti- der schieden, dass die Witwe vor dem Ausonen getätigt wurden und der mittlerweile zug noch genug Geld erübrigen konnte, eine heranwachsende Forst einen Mehrwert »Nitzsche-Stiftung " vor Ort ins Leben zu rechtfertigen würde. Auf Seiten der Käufer rufen, die der Linderung von Not und Sorge wiederum bestanden Probleme, Kredite bei bei den Gemeindemitgliedern dienen sollte Geldinstituten zu akquirieren, da gerade ein und Senffts - wie sich bereits abzeichnen allgemeiner Geldmangel herrschte. sollte - das vollkommen sanierungsbedürftige Schloss zum Anlass nahmen, es vollEin Gutachten fasste 1907 die Fakten zusam- kommen neu auszustatten. ${ }^{85}$ Die Dorfgemen. Zum Verkauf standen: 275 ha Waldbe- meinschaft verabschiedete die ehemalige Eistand, 185 ha Feld, 50 ha Wiese, 10 ha Park gentümerin und begrüßte auch die neuen und Garten, 5 ha Fohlenkoppeln, 1 ha Teiche durch zwei Ehrenpforten und Ansprachen. und Wege, also 526 ha Gesamtfläche mit al- In den Akten finden sich mehrfach Hin- 


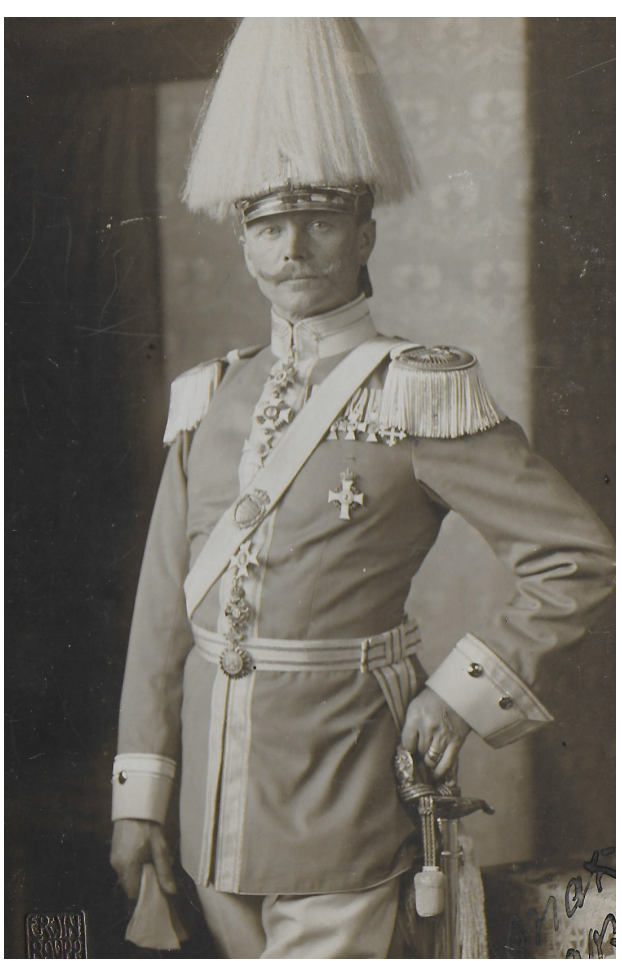

14 | Friedrich Hugo Maximilian Senfft von Pilsach (1855-1931) (Privatarchiv von Friesen, Dresden).

weise, dass sich die Gutsherrschaft bis ins 20. Jahrhundert hinein an kommunalen, sozialen und karitativen Aufgaben beteiligte. ${ }^{86}$

\section{Reinhardtsgrimma im 20. Jahrhundert:} Senfft von Pilsachs

Der Käufer, Friedrich Hugo Maximilian Senfft von Pilsach auf Röpsen und Groß Prießlich bei Gera (1855-1931), entstammte einer im Militär erfolgreichen uradligen Oberpfälzer Familie (Abb. 14). In der Überlieferung findet man den Hinweis, dass er das ("230 ha ${ }^{87}$ große) Rittergut Böhlen verließ, da der nahende Braunkohleabbau das dortige Leben erschwerte. Neben den besagten Gütern besaß Senfft in der Radeberger Straße 14 in Dresden eine Stadtwohnung. Als 1891 sein Onkel Anton von Helldorff auf Böhlen (geb. 1826) kinderlos starb, erbten zunächst seine Schwester Marie und der angeheiratete Schwager Werner Christoph Da-

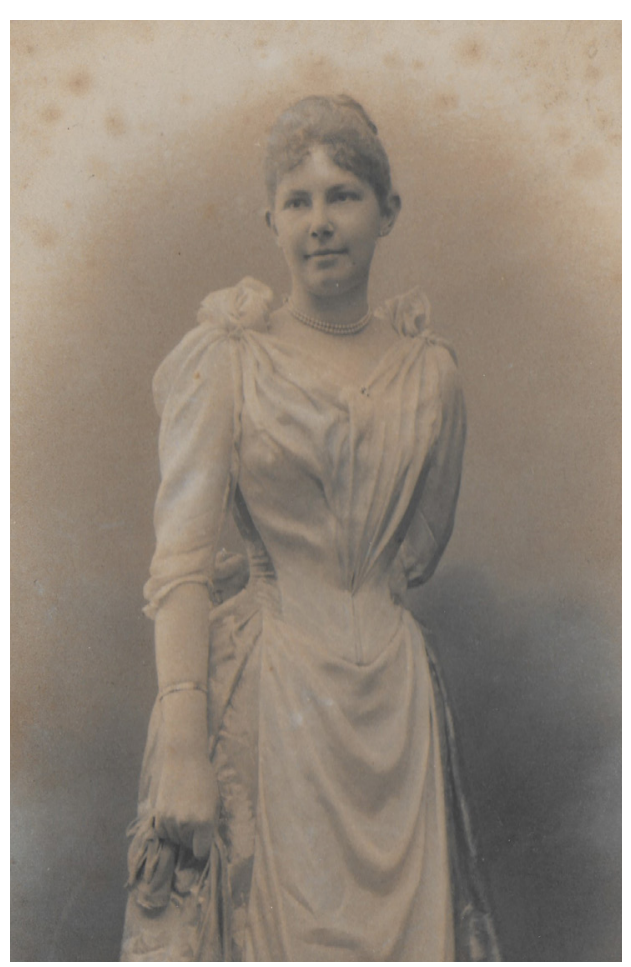

15 | Alpheda Louise Teding van Berkhout (1863-1959) (Privatarchiv von Friesen, Dresden).

niel von der Schulenburg, wobei sie das Erbe ausschlugen. ${ }^{88} \mathrm{Um}$ das mütterliche Familiengut zu halten, wurde es möglicherweise entschuldet und geriet infolgedessen an Maximilian von Senfft. Dementsprechend behielt er Böhlen auch nach dem fürs Frühjahr 1908 terminierten Einzug in Reinhardtsgrimma aufrecht, wobei Teile des Gutes vermietet und zunehmend an verschiedene Interessenten verkauft und verpachtet wurden. In den Archivalien finden sich u.a. Vermietungen des Herrenhauses, aber auch des Jagdschlosses" sowie der Jagd. Man bemühte sich, den seit 1901 für 4.300 Mark Abgabeleistungen wirtschaftenden Pächter Curt Töpfer bis $1925 \mathrm{zu}$ halten und scheint sogar (für 1910 belegt) noch einen Gärtner namens Hinke dort zu beschäftigen; dem Mieter - einem Herrn von Querfurth - trug man auf jeden Fall auf, keine Fällungen oder Veränderungen im Gutspark vornehmen zu

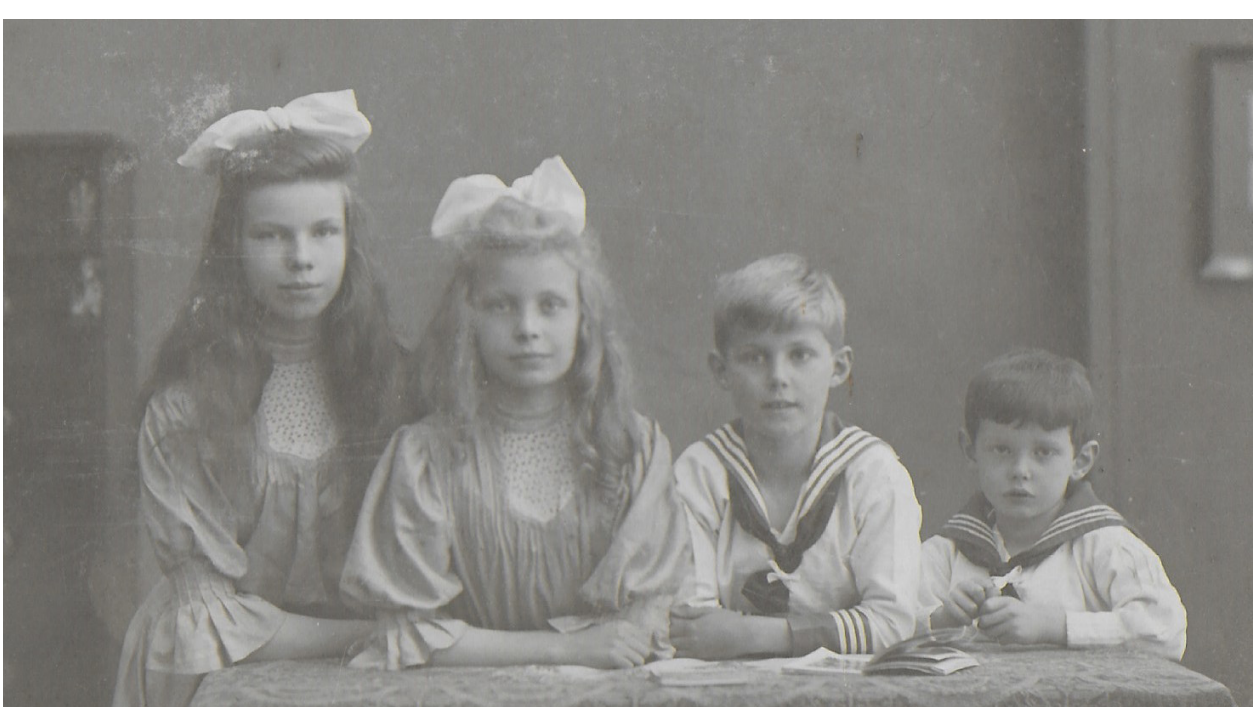

16 | Fotografie der vier Geschwister Senfft von Pilsach von links nach rechts: Louisa - Auguste - Hugo - Ott 1908 in Holland aufgenommen (Privatarchiv von Friesen, Dresden).

ber von »Onkel Anton" und »Onkel Os- (1900-1917) und Ott Friedrich (1903-1988). wald « in Böhlen pflegte, wie eine Abrech- Eine erstgeborene Tochter starb bereits nung nahelegt. ${ }^{90}$ $1894 .{ }^{92}$ Die Kinder sind auf Abbildung $16 \mathrm{zu}$ sehen.

Eine wesentliche Kraft hinter dem Unterhalt

von Böhlen aber auch dem Kauf und Aus- Ein im Archiv hinterlegtes Adressbuch, das bau Reinhardtsgrimmas scheint Alpheda hilft zahlreiche Kontakte nachzuweisen, wie Louise Teding van Berkhout (Batavia 1863- sie sich durch familiäre, ständische, wirt1959 Meran) gewesen zu sein (Abb. 15), die schaftliche und soziale Beziehungen ergeihren Mann, Maximilian von Senfft, wahr- ben, konnte bislang noch nicht erschlossen scheinlich über ihre Halbschwestern ken- werden. Doch scheint es, dass der Austausch nengelernt hatte, waren doch beide mit ehe- landwirtschaftlicher Erneuerungen oder die maligen Kameraden ihres Mannes verheira- Anstellung von Gärtnern, ja selbst der Kauf tet: Die ältere, Maria (1858-1949), ehelichte von Hunden nicht dem Zufall überlassen 1881 George Francois Edward von Olhoff waren, sondern dass man ein gesellschaftliGroote (1857-1927), Leutnant in der sächsi- ches Netzwerk pflegte, das sich sehr eng an schen Kavallerie, und die jüngere, Louise familiäre Bindungen und Standesgrenzen (1860-1939), heiratete 1884 den Oberstleut- hielt.93

nant Carl Friedrich August Alexander von Luttitz auf Tzschernitz (1859-1917).91

Die finanziellen Mittel, über die das Gutsarchiv nur punktuell Auskunft gibt, scheinen Als dritte Tochter und letztes Kind ihres Va- größtenteils von Alpheda zu stammen, de ters vermählte sich Alpheda 1893 in Den ren Familie seit 1872 die bis 1958 existierende Haag und schenkte ihrem Mann fünf Kin- >Tjomal Suikeronderneming in Indonesien der: Louisa Alpheda >Isa< (1895-1969, seit gehörte. Angehörige dieser im 16. Jahrhun1918 verh. Gräfin Hohenthal und Bergen), dert geadelten Familie waren, später als InAuguste Marie `Gustie`(1897-1989, verh. genieure, Politiker und Industrielle sehr ervon Schönberg auf Oberreinsberg), Hugo folgreich. Zeitweise arbeiteten 13.00o Perso- 
nen in dem Unternehmen, das auch Arrak getrennt und als Sonderinvestition behanherstellte. Über Alpheda heißt es: »Indeed, delt wurden. Die in den Archivalien auftauin the 1930s the largest single shareholder in chenden Hinweise auf die Vermögensverthe Tjomal sugar company was [...] Al- hältnisse der Familie lassen jedoch den pheda [...].«"14 In den Archivalien tauchen Schluss zu, dass sie sehr wohlhabend geweimmer wieder regelmäßige Überweisungen sen sein muss. Spätestens 1909 wurde beiaus den Niederlanden auf (1905/06 bei- spielsweise ein Fiat angeschafft, den man spielsweise monatlich zwischen 1.300 und vermutlich um 1911 durch einen Mercedes 1.50o Mark sowie Sonderzahlungen aus Tjo- (Abb. 17) ersetzte..$^{95}$

mal), wobei man sich nur schwer ein Ge-

samtbild machen kann, da das holländische Auch besaßen die Kinder - nach heutigem und das deutsche Vermögen bzw. Privat- Umrechnungskurs - zum Ende des Ersten und Geschäftsvermögen wohl weitgehend Weltkriegs je ein Vermögen von über einer Million Euro. Als ungewöhnlich dürfte zudem gelten, dass man 1936 einen Privatflughafen neben der Schäferei unterhielt, der auch als Wiese genutzt wurde. ${ }^{96}$

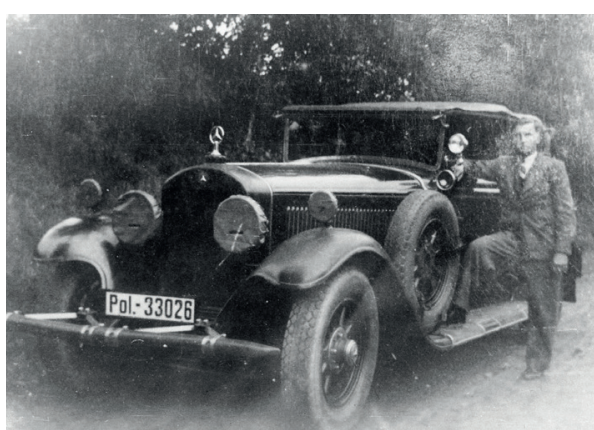

17 | Fotografie des Mercedes mit Chauffeur, ca. 193 (Heimatverein Reinhardtsgrimma).

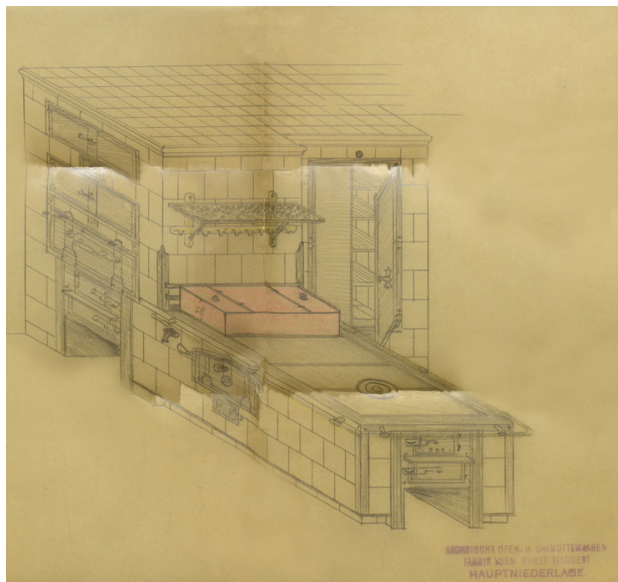

18 | Entwurf einer komplexen Kochmaschine mit Wärmeschrank von der Sächsischen Ofen- und Chamottewarenfabrik Meißen, Bleistiftzeichnung, 1908 (SächsHStA, 10505, Nr. 104, Rechnungen, Baupläne Lohnlisten, Kostenvoranschläge und Kautionsverzeichnisse zum Umbau des Schlosses Reinhardtsgrimma einschließlich der Wirtschaftsgebäude 1907-1909).
Tatsache ist, dass die Maßnahmen zum Umund Ausbau sowie zur Sanierung des Schlosses und der Wirtschaftsgebäude nicht nur von 1907 bis 1909 dauerten, sondern auch die ungeheure Summe von 307.164 Mark $^{97}$ verschlangen, die größtenteils für das Schloss aufgewandt wurde. Die Kosten verursachten dabei nicht nur Modernisierungen, wie etwa 1902 der Einbau einer erweiterten Heizungsanlage, eines Speiseaufzugs oder einer silbergrauen Kochmaschine (Abb. 18), sondern auch Restaurierungen, da Gegenstände erneuert oder kopiert wurden. Zudem schaffte man geschmackvolle Neuausstattungen an (Abb. 19 und 20). Die Oberaufsicht hatte vermutlich der mehrfach in den Akten auftauchende königliche Hofbaurat Gustav Frölich (1855-1933) inne, der gerade beim Wiederausbau des barocken Schlosses Lichtenwalde (1905-1909) sein Können zeigen konnte. Die fast zeitgleich von ihm initiierte Innenausstattung des Schlosses in Zschorna (1909) und der Ausbau des Schlosses in Waldenburg (19091913) belegen, dass er seitens der Senffts als Fachmann für Anpassungen eines Schlosses an moderne Bedürfnisse angesehen wurde..$^{98}$ Die Unterlagen bezüglich des Umbaus ind äußerst reichhaltig, wobei vor allem deutlich wird, dass die Ausstattung der Räume luxuriös war: neue Vertäfelungen

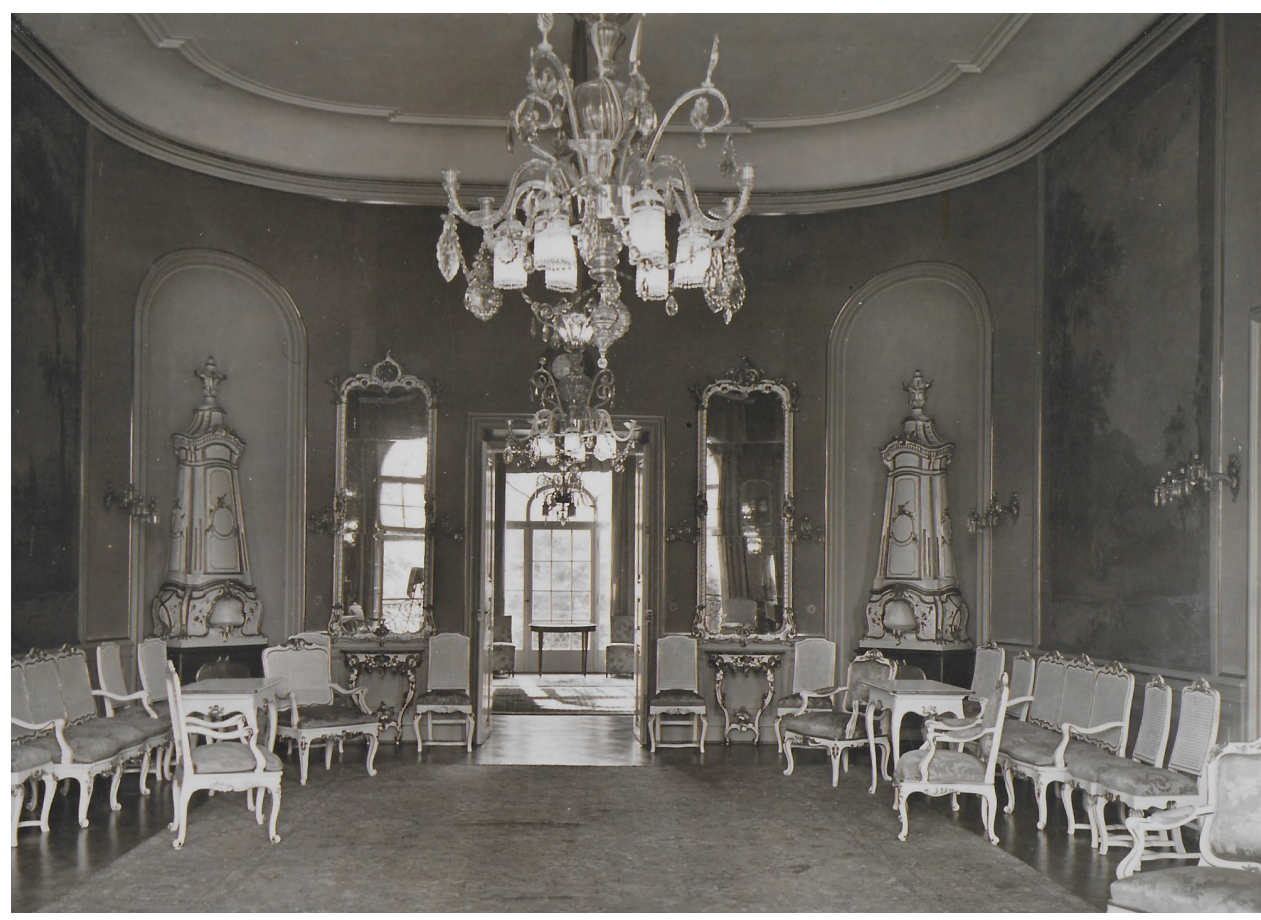

19 | Blick in den Festsaal vor 1945 (Privatarchiv von Friesen, Dresden).

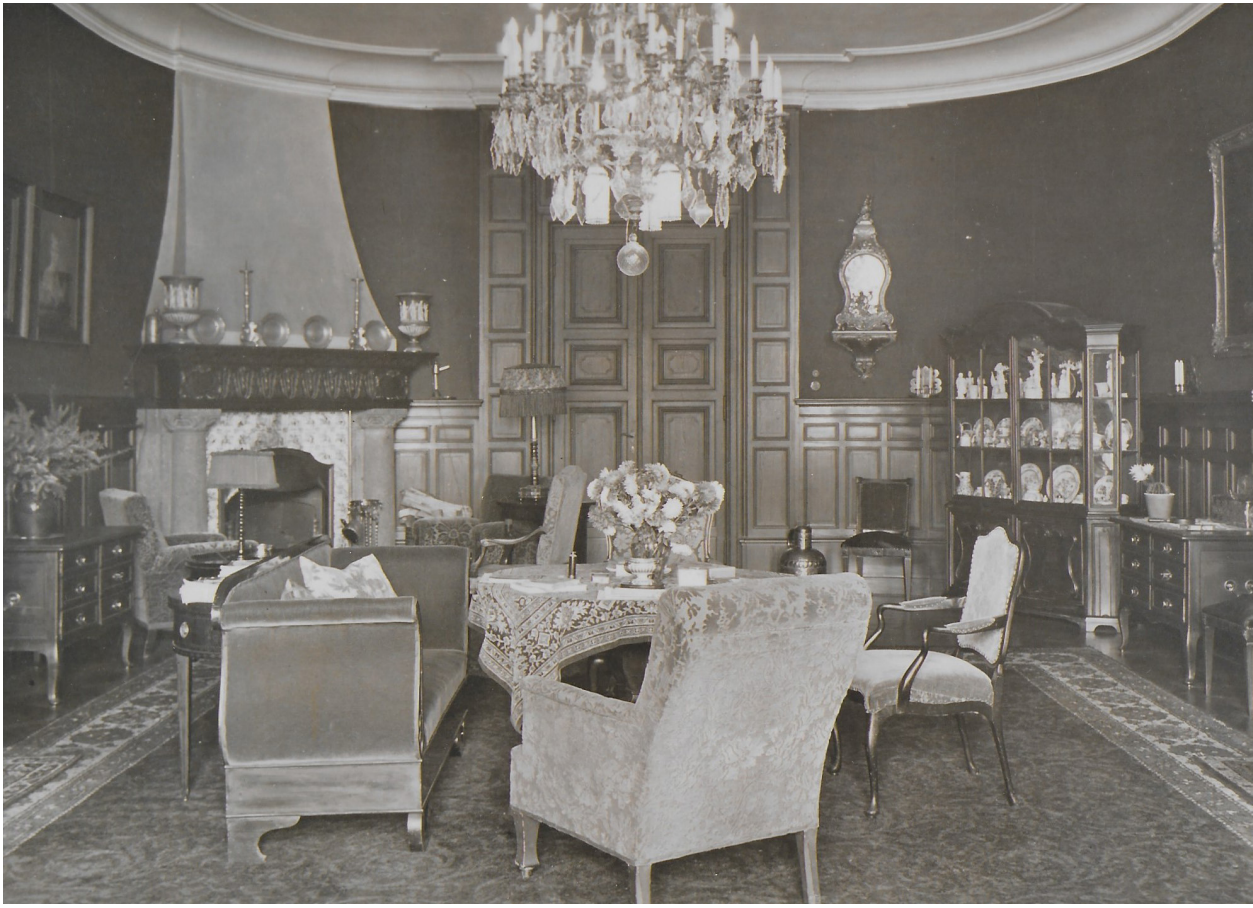

20 | Blick in die Wohnhalle vor 1945 (Privatarchiv von Friesen, Dresden). 


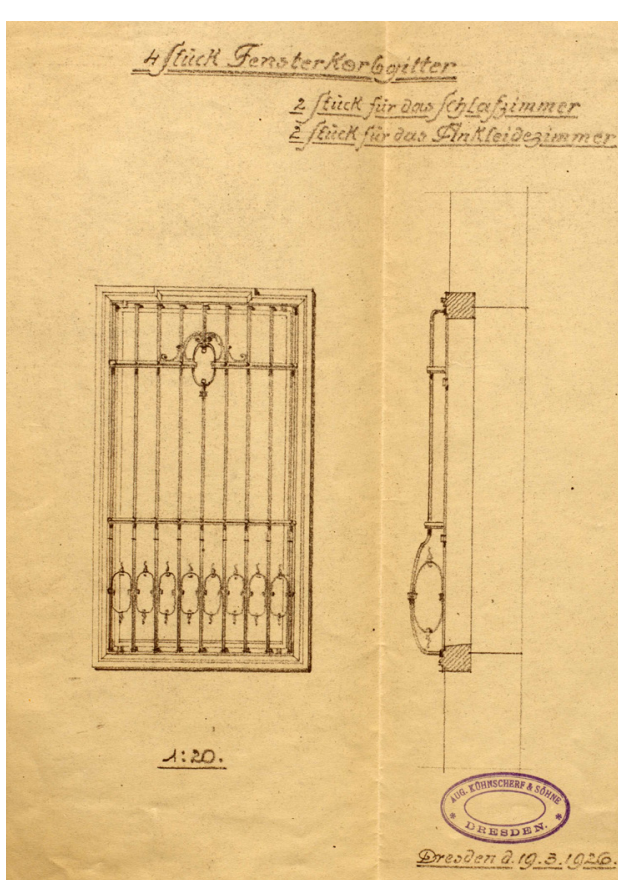

21 | Entwürfe für Fensterkorb-und Türgitter von der Firma Kühnscherf und Söhne, Lichtdruck, 1926 (SächsHStA, 10505, Nr. 509, Drei Skizzen zur baulichen Datum).

wurden eingebracht, neun Tonnen Setzdorfer Marmor und Kalk (heute: Vápenná, Tschechien) verbraucht, zudem waren Bildhauer und Stuckateure beschäftigt, Ornamente anzubringen und zu ergänzen. Rokokospiegel und -kamine wurden neu geschaffen oder eingefasst, und wahrscheinlich gelangten in dieser Zeit nicht nur die niederländischen Leinwandtapeten in den Festsaal, sondern auch die wiederverwendeten Delfter Kacheln an die Wände und in die Kamine. ${ }^{99}$ Der Einbau von Delfter Fliesen, der ebenfalls an eine im 18. Jahrhundert im norddeutschen Raum verbreitete Mode erinnerte (Caputh, Wrisbergholzen, Hünne- Obwohl die Biographien und wirtschaftlifeld, Oranienbaum), verwies zudem auf die chen Geschicke von Alphedas Eltern, dem Heimat der Schlossherrin. Hofhandwerker Ingenieur Willem Hendrik Teding van Berkgaben sich buchstäblich - die ebenfalls ar- hout (1830-1917) und Johanna Petronella chivalisch belegte, da kopierte - Türklinke Sophia van der Wijk (1837-1927), eng mit Inin die Hand, wie etwa der dem Jugendstil zu- donesien verbunden sind, darf man nicht geneigte Kunst- und Dekorationsmaler Ju- vergessen, dass sie mit ihrem Alters- und lius Schultz (Rechnungen über knapp 2.00o Familiensitz Kasteel Groot Hoenlo in Olst

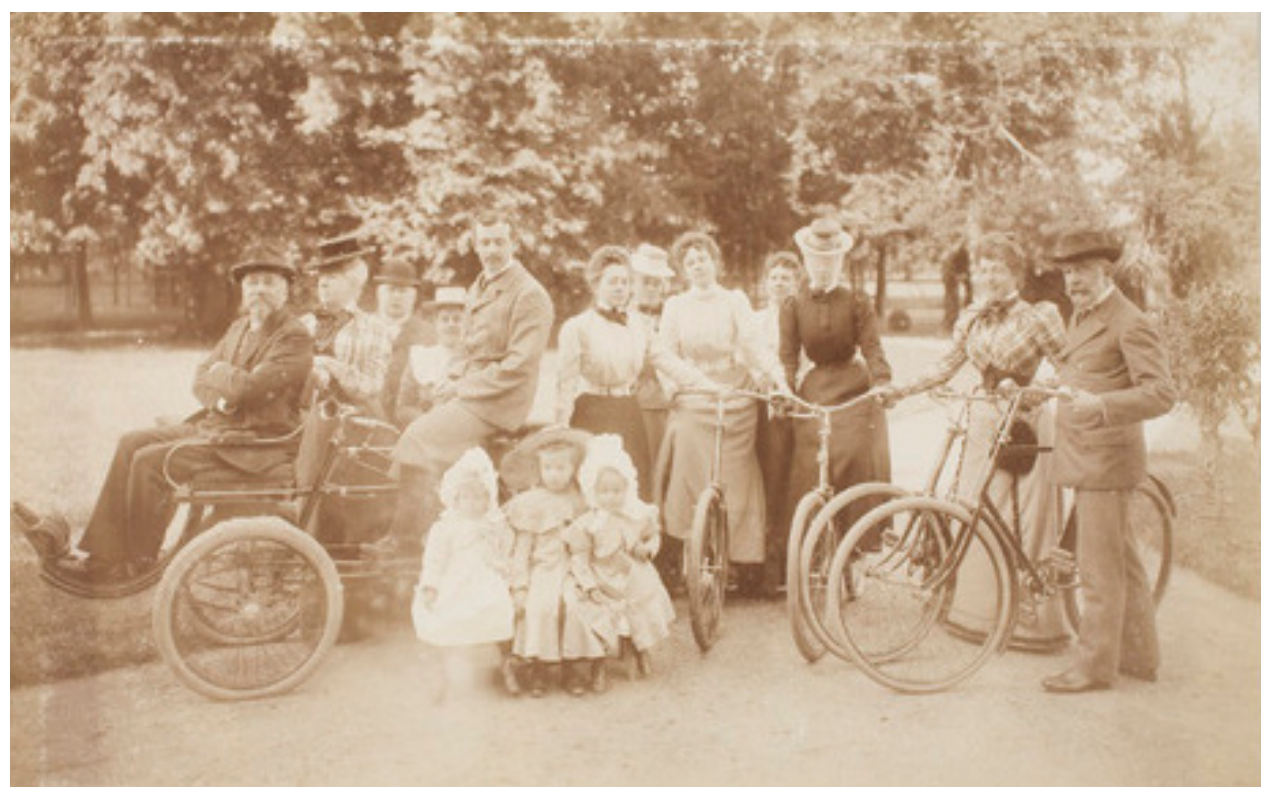

22 | Fotografie der Familie Teding van Berkhout in Olst/ Niederlande, September 1899 (Rijksarchief, https://rkd.nl/ nl/explore/images/163812). Links sitzend Willem Hendrik Teding van Berkhout, dahinter stehend seine Frau Johanna Petronella Sophia, geb. von der Wijk. Auf dem Fahrrad sitzend F.W. des Tombe, daneben stehend seine erste Frau van Olhof Grote. Am rechten Bildrand Freiherr Senfft von Pilsach.

einen gesellschaftlichen Treffpunkt schufen. (den »Eisernen Max« wie er anerkennend in So gibt es nicht nur ein Familienfoto im militärischen Kreisen hieß) hin, der nach Rijksarchief (Abb. 22), auf dem auch das seinem 1917 gesundheitlich bedingten AusEhepaar Senfft in Hoenlo zu sehen ist, son- scheiden aus der Armee berichtete: „Still dern auch entsprechende Ortsnennungen lebte er nun auf seinem Besitz Reinhardtsim Gutsarchiv Reinhardtsgrimma. Eine we- grimma [...] und widmete sich der Landsentliche Anregung mag jedoch von dem wirtschaft. $\aleph^{103}$

zwischen 1895-97 durch Johannes Jacobus Dieses Interesse ist zunächst nicht durchvan Nieukerken (1854-1913) initiierten Um- gängig, spiegelt sich aber an einigen, gerabau des elterlichen Hauses ausgegangen dezu modernistischen Punkten: So ließ man sein, der nämlich - ähnlich wie in Reinhard- 1927 beispielsweise von der Firma »Arthur tsgrimma ablesbar - die zwischenzeitlich Müller Land- und Industriebauten " eine verbaute Substanz des Barock nicht nur wie- neue Feldscheune errichten. Müller, der das derherstellte, sondern auch modernisierte. ${ }^{102}$ Unternehmen 1908 gründete, war vor allem durch seine Scheunen in Leichtbauweise, Der lukrative Erwerb des wirtschaftlich in- aber auch durch die Konstruktion von Baltakten Ritterguts erscheint vor dem Hinter- lon- und Luftschiffhallen berühmt geworgrund einer erfolgreichen militärischen den. Passenderweise ließ man auch die OsKarriere aber auch den Einkünften Alphe- terrieder-Gesellschaft mbH aus Memdas sinnvoll, da sich dem Ehepaar Senfft mingen den dort 1908 erfundenen Höhenhierdurch die Möglichkeit eröffnete, ge- förderer anliefern. ${ }^{104}$ Daneben wendete man meinsam ein familiäres wie wirtschaftliches 1920 die modernsten Fütterungsmethoden Standbein zu schaffen. Hierauf deutet auch an und verabreichte Palm-, Erdnuss- und ein Nachruf auf den Generalmajor Senfft Leinkuchen sowie Zahnmais. ${ }^{105} 1927$ wurde 
- wie die überkommenen Fotografien (vgl. Beitrag "Zwischen Physiokratie und Landschaftsverschönerung", Abb. 5) zeigen - ein neues, komfortables Forsthaus durch den Baumeister Wilhelm Reichel aus Cunnersdorf errichtet. ${ }^{106}$ Dass man seitens des Ritterguts ein verträgliches Einvernehmen mit der Gemeinde anstrebte, belegen nicht nur übernommene Entschuldungen im Jahr 1920, sondern auch eine Landschenkung, die zur Gründung der heute noch existierenden Sportanlagen führte.

Mit dem Tod des Gutsherren 1931 nahm jedoch die Geschichte eine andere Wendung, wie man in der Familienchronik nachlesen kann: Die Witwe erhielt wieder die holländische Staatsangehörigkeit, so dass sie als Nicht-Deutsche drei Monate im Jahr im Ausland leben musste. Über ihr Schicksal im Zweiten Weltkrieg und danach liest man:

»Im April 1945 treckte Alpheda mit ihrer Hausdame Virginia von Roenne, einer von allen sehr geliebten Baltin, und einem alten Ehepaar über das Erzgebirge in die Tschechei. Sie wurden ausgeplündert, trotz der holländischen Fahne, welche aus ihrem Pferdewagen heraushing. Sie kamen zurück nach Reinhardtsgrimma und machten sich kurz bevor die Russen kamen wieder mit Pferd und Wagen auf den

Weg nach Westen und später mit großen Strapazen zur Tochter Isa v. Hohenthal nach Oberbayern. Die Tochter Auguste v. Die denkmalpflegerisch begleiteten RenoSchönberg treckte mit ihrem Mann Wolf vierungen haben in der Nachwendezeit am und ihren fünf Kindern ebenso von Sach- Schloss und im Garten historische Spuren sen nach Oberbayern. Der Sohn Ott, aus gesichert, ergänzt und wieder erlebbar geder Gefangenschaft kommend, fand sich macht (Abb. 24). Die Privatisierung der ehedort ein. 1946 oder 47 fuhr Ott nach Me- maligen Gutsgebäude ist jedoch heute noch ran, um nach dem Besitz seiner Mutter zu schmerzlich spürbar, da sie teilweise massiv sehen, sie hatte ihn 1936 gekauft. Ott umgebaut wurden oder gar leer stehen. wurde sofort von den Italienern verhaftet, Hierzu gehört auch der Neubau des Quernach Rom gebracht, wo er viele Monate riegels vor dem westlichen Teil des Schlosmit Schwerverbrechern und ohne Ver- ses, der den Gutshof von der Hauptfassade höre im Kerker saß. Ein Jahr später be- abtrennt.

kam Alpheda als Holländerin ein Visum für Italien und lebte bis zu ihrem Tode Ott hat mit viel Geschick und Fleiß das alte Haus wohnlich gemacht, die Obstund Apfelwiesen gepflegt und 1973 auch eine Holländerin geheiratet, Petronella,

Nach der Enteignung (Gärtnerei, Sägewerk, kerei, etc.) wurde der Besitz mverteilt, das heißt unter anderem wurden 331 ha Land (inklusive 282 ha Wald) auf 45 Jahr 1946 eröffnete man die Landwirtschaftiche Fachschule mit Internat. ${ }^{108} 1952 \mathrm{kam}$ war, nach Reinhardtsgrimma. ${ }^{109}$ Er sollte die Umbaufähigkeit untersuchen und sah noch tliche Ausstattungsreste, die zunehmend richtsräume integriert wurden. ${ }^{110}$ Das prächkeine Ambitionen mehr besaß und im ut nur noch ein Nutzobjekt sah. Dabei wahllos aus dem einstigen Ensemble herausetrennt. welche noch dort lebt. «107 er Dresdner Architekt Fritz Steudtner

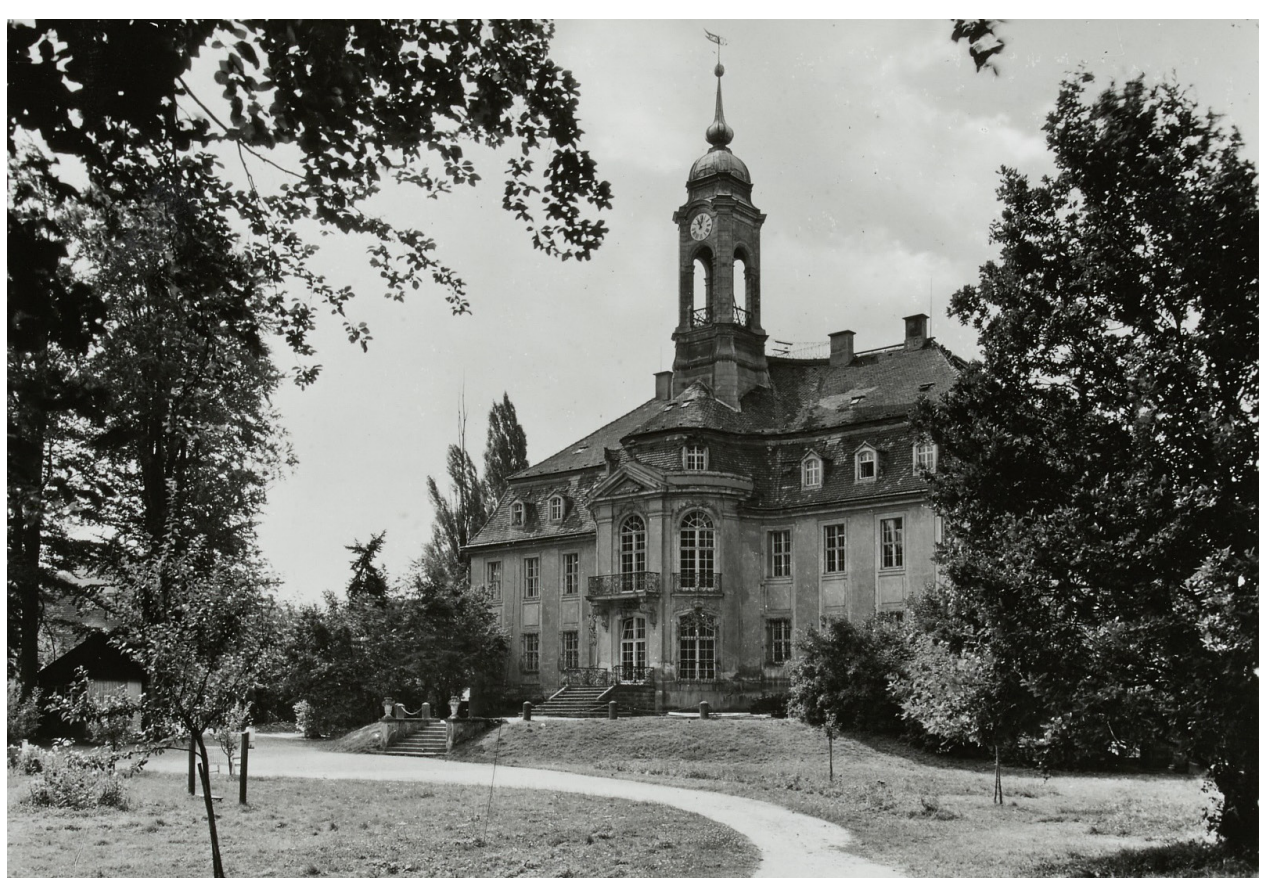

23 | Ansicht des Schlosses von der Gartenseite, Verlag A. und R. Adam, 1953 (SLUB, Deutsche Fotothek, df_hauptkatalog_0354929.

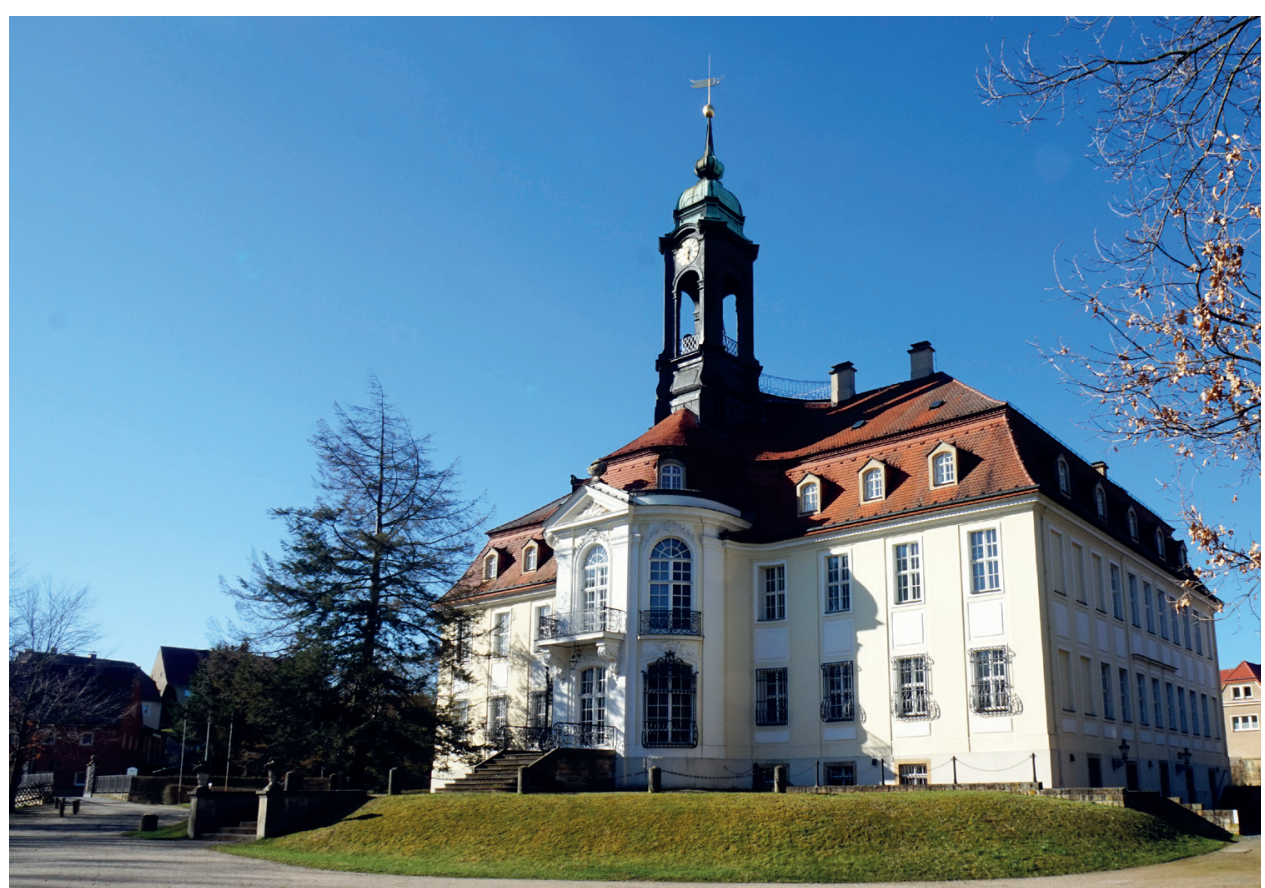

24 | Aktuelle Gegenüberstellung, Fotografie: Anja Gottschalk, April 2021. 
Grundlegend sind: Vollständiges Staats- Post und Zeitungs-Lexikon von Sachsen von 1822, S. 81-86 Sachsens Kirchengalerie: Fünfte Abtheilung. Die Inspectionen Pirna, Altenberg und Dippoldiswalde Dresden 1840, S. 100-106; Poenicke, Gustav Adolf (Hg.): Album der Rittergüter und Schlösser im Königreich Sachsen, 1856, Band 2, S. 163-164 Krauße, Johannes: Reinhardtsgrimma. Die Geschichte des Bevölkerungsaufbaues eines sächsischen Dorfes, o.O., 1937; Schmidt, Otto Eduard Reinhardtsgrimma - Ein Ort und ein Schloß abseits der großen Heerstraße, Sonderabdruck des Sächsischen Heimatschutzes Dresden, Jahrgang 30, 1941 1/4, S. 1-26; Tinius, Heinz: Festschrift zur 750 Jah Feier von Reinhardtsgrimma 1956, O.O. 1956; Müller, Gerhardt: Zwischen Müglitz und Weiss, ler, Gerhardt. Zwischen Muglitz und Weisseritz : Ergebnisse der heinatkundichen BestandsaufBerlin 1964 .

2 Schiffner, Albert: Beschreibung von Sachsen, Stuttgart 1840, S. 46.

3 Schmidt 1941, S. 4. Nach Hinweis von Ute Essegern und Peter Wiegand (beide Leitung Hauptstaatsarchiv Dresden) könnte der Plan auch um 1614 datiert werden, da zu dieser Zeit Erwerbsverhandlungen Kurfürst Georgs I. mit dem auf dem Plan verzeichneten Fritz von Mangoldt geführt wurden. Am Ende übernahm der Kurfürst nur die Jagdrechte (SächsHStA, 10505, Nr. 527). Vergleiche dazu: Wiegand, Peter: Ein manregister unserer landschafft. Die kursächsische Landesaufnahme des 16. Jahrhunderts als Herrschaftsinstrument und Repräsentationsmedium, in: Baumgärtner, Ingrid (Hg.): Fürstliche Koordinaten: Landesvermessung und Herrschaftsvisualisierung um 1600, Dresden 2014, S. 140.

4 SächsHStA, 10505, Nr. 541, Erbregister 1624

Die jüngsten Waldbestände auf der Forstkarte von 1807 sind 20 Jahre alt. Das heißt, es wurde etwa ein Jahrhundert früher aufgeforstet. Teils überziehen die Fläche wesentlich ältere Bestände (vgl. Beitra ZWischen Physiokratie und Landschaftsverschönerung «).

6 Tielke, Johanna Gottlieb: Beytraege zur Kriegs Kunst und Geschichte des Krieges von 1756 bis 1763,Band 1, Freyberg 1775, darin: Das Treffen bei Maxen. Zu den detaillierteren Kriegsfolgen s.a. Tinius 1956, S. 47-57, ohne Nachweise. Johann Heinrich Zedler: Grosses vollständiges Kïnste. Bend 42, Lepzig 1744, Z 1484. In de lokaKunste. Band 42, Leipzig 1744, Z. 1484. In der lokalen Geschichtsschreibung taucht auch inmer wieder Agnes Cather mit dem Obristen Hans Heinrich von Venedige (1684-Belgrad 1737) verheiratet war. Sie war eine Halbschwester des Erblassers. Venediger selbst wird auch als auf Reinhardtsgrimma ansässig beschrieben, siehe: Hof- und Staatskalender auf das Jah 1735, Leipzig 1734, unpaginiert; Bei der Erbhuldigung 1733 sitzt Obrist Venediger an der Marschallt fel.
Aus seiner mit Johanna Friederike Ernestine von Hagen (1736-1775) 1763 in Reinhardtsgrimm geschlossenen Ehe, entstanmte der noch 1765 dort geborene Karl Ernst Wilhelm. Jahrbuch des deutschen Adels,Band 3, Berlin 1899, S. 37 off

Vgl. sowohl 10025 Geheimes Konsilium Loc. 05688/04, sowie 10026 Geheimes Kabinett, Loc. o130o/16. Zur Problematik vgl. Flügel, Axel: Bürgerliche Rittergüter, Sozialer Wandel und Politisch Reform in Kursachsen (1680-1844), Göttingen 2000, S. 211, der die 193 Rittergüter des Leipziger Kreises untersuchte.

SächsHStA, 10084 Appellationsgericht, Nr. 07265 Ein Christian Lippold, »Ratsverwandter sowi Kauf- und Handelsmann« aus Dresden, wird schon 1729 als Besitzer des Vorwerkes in Berreuth Es gilt zu klären in vieweit es sich hier um den Vater von Johann Christoph hes sits da er um den Vater wird, ir. Nr. 03392, 10052 Amt Grillenburg, Nr. 097

11321 Generalkriegsgericht, Nr. 1220

Scholze, Hans Eberhard: Johann Friedrich Knöbel: ein sächsischer Landbaumeister im 18. Jahrhundert Seminararbeit Baugeschichte an der TH Dresden, 1952, o.S. Die Arbeit ist im wissenschaftlichen Gedankengang äußerst wertvoll, enthält jedoch ungenaue und falsche Angaben, so dass sie im Folgenden nicht mehr zitiert wird. Zitat bei: N.N Kleine Chronik der Kirche in Reinhardtsgrimma, o.O., o.J., (S. 98, unpaginiert)

Zweites Dokument aus der Turmkugel des Schlosses Reinhardtsgrimma vom 23.06.1843 - Verfasser Pfarrer P. K. Brückner, in: Grimmsches Heimatblatt, Heft Nr. 4, 12/2009.

4 Hentschel, Walter: Die sächsische Baukunst des 18 Jahrhunderts in Polen, Textband, Berlin 1967, S. 75-78. Zur Zuschreibung: Hasche, Johann Christian (Hg.): Magazin der sächsischen Geschichte, Teil Dresden 1784, S. 341

5 Hentschel, Walter; May, Walter: Johann Christoph Knöffel, Der Architekt des sächsischen Rokokos, Berlin 1973, S. 57 .

6entschel 1967, S. 78, weist auf eine Besonderhei auf diesem Plan (in: SächsHStA, 10505, Nr. 409) hin: "Eine weitere Eigentümlichkeit von Knöbels Plänen ist die Bezeichnung des Ellenmaßstabes mit "Ellen Dresdner" oder "Aunes de Dresde", die nur bei ihm - freilich nicht ausschließlich - neben "Ellen", "Aunues" und "Aunues de Saxe" vorkommt.."

Seidl, Carl von: Versuch einer militärischen Geschichte des Bayrischen Erbfolgekrieges, Königsberg 1781,Band 2, S. 204f.

SächsHStA, 10505, Nr. 520, Verkauf des Rittergutes Reinhardtsgrimma durch die Erben von Johan Christoph Lippold an Henning von Rumohr fü 71.000 Taler 1781-1782. Als Erben werden genannt Maria Sibilla Junghannß (verh. mit Samuel Heinrich Junghannß, Erzdiakon in Meißen), Christian Dorothea Mylius (verh. mit Floß-Kommissar Ernst
Mylius); Johann Gottfried Lippold, Amtmann Johann Gotthelf Lippold, Kavallerie-Lieutnant Christoph Conrad Lippold; Johanna Eleonora Weiß (verh. mit Jacob Heinrich Weiß, Kammer-Kommissar); Johanna Carolina Hiller (verh. mit Johan Friedrich Hiller, Artillerie Obrist); Carl Christoph Lippold; Johann Gottlob Lippold, Kammer-Sekretär; Johanna Charlotte Lippold; Johanna Friederike Schmidt (verh. mit Friedrich August Schmidt, Geheimer Kabinetts-Sekretär) - ist bereits 178 gestorben.

19 Ebd., Nr. 521, Kauf des Rittergutes Reinhardtsgrimma durch Johanna Joachime Charlotte Racknitz für 95.500 Taler im Jahr 1800 . Dort auch entsprechendes Inventar

20 Zur nordelbischen Besitzung siehe: Kraft, Jens: Topographisk-Statistisk Beskrivelse over Kongeriget Norge,Band 1, Christiana [Oslo] 1840, S. 339.

21 Österreichischer Beobachter, 26.9.1811, S. 1078 [Nachrichten aus Dresden] Dort auch Nennung von Herzhorn. Die Besitzung wurde nach ihm auch "Bülowsche Wildnis« benannt, s. Bülow, Jakob Friedrich Joachim und Paul von: Familienbuch der von Bülow, Berlin 1858, S. 281.

22 Fjelstrup, A.: Damerne ved Karoline Matildes Hof Kopenhagen 1909, S. 113-122.

23 Österreichischer Beobachter, ebd.; zur Biographi siehe Bobé, Louis: Papirer fra den Reventlowsk Familiekrads,Band 3, 1896, S. 398, sowieBand 7 1906, S. 465. Die Verbindung zwischen Dannes-
kiold-Laurvig und Bülow läuft sehr wahrscheinlich kiold-Laurvig und Bülow läuft sehr wahrscheinlic über ahlefeldtsche Verwandte.

24 Das Stammbuch Friedrich von Matthisons, Transkription und Kommentar, Gottingen o.j., S. 371.

25 Böttiger, Karl August: Joseph Friedrich Freiherr Racknitz, Worte der Bruderliebe... 1818; Bärnighausen, Hendrik; Coban-Hensel, Margitta: Joseph Friedrich Freiherr von Racknitz (1744-1818). Seine "Darstellung und Geschichte des Geschmacks de vorzüglichsten Völker« und ein Ausstattungsprojelt für Schloss Moritzburg (1792/1793), Jahrbuch de Staatlichen Schlösser Burgen und Gärten Sachsen,Band 11 (2003), S. 41. Siehe auch Einleitun in: Jervis, Simon Swynfen: A Rare Treatise on Interior Decoration and Architecture - Joseph Fridrich

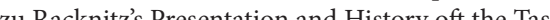
oft the Leading Nations, Los Angeles 2019 .

26 Johanna Margarete, Tochter von Gallus Maximilian von Racknitz, erbte das Gut von ihrer Mutter Franziska Henriette geb. von Flemming-Ringetal.

27 Erinnert sei hier an die Pflanzenscherenschnitte Philipp Otto Runges aus der gleichen Zeit, vgl. Bertsch, Markus (Hg.): Kosmos Runge. Der Morge der Romantik, München 2010, S. 360-371; Fuessl Johann Rudolf: Allgemeines Künstlerlexikon, Zürich 1812, 2. Teil., 1192f.

28 Racknitz, Joseph Friedrich von: Briefe über die Kunst an eine Freundin, Leipzig 1795. Für dieses Werk werden zwei architekturbezogene Tafeln von einem Knobel gezeichnet - die Nennung des Vornamens fehlt auf den Tafeln. Möglicherweise handel es sich um den o.g. Baumeister, seine Stiche müssten dann spätestens in seinem Todesjahr 1792 dem Buc beigefügt worden sein

29 SächsHStA, 10505, Nr. 247, Testament von Friedrich Ludwig Ernst von Bülow (Abschrift) 1802.

o Ebd.

In der Kleinen Kirchenchronik, recherchiert und abgefasst von Otto Friedrich Hiecke - von 1931 bis 1962 Pfarrer in Reinhardtsgrimma - wird von ihre "Gesellschaftsdemoiselle« Colombe Trance gesprochen, die 1821 im Alter von 68 Jahren verstarb.

32 SächsHStA, 10505, Nr. 517, Abschrift der Quittun zur Übergabe des Rittergutes Reinhardtsgrimma an Johanna Joachime Racknitz 1809: dort wird auch von einer seit 1808 ausstehenden Übergabequittun betreffs des Guts berichtet. Kaufvertrag SächsHStA 10505, Nr. 512

33 Ebd., Nr. 249, Übergabe des Rittergutes Reinhardtsgrimma an Friederike Juliane Christiane von Bülow (Schenkungsurkunde) 1806

Öhlenschläger, Adam: Meine Lebens Erinnerungen,Band 2, Frankfurt/Main 2018, S. 57.

Bülow 1858, S. 128 f. und S. 281 .

36 Steche, Richard: Beschreibende Darstellung de alteren Bau- und Kunstdenkmäler des Königreich Sachsen,Band 2, AH Dippoldiswalde, Dresden 1883

SächsHStA, 10505, Nr. 251, Kostenvoranschlag fü noch fertig zu bauende Gebäude 181

Ebd., Nr. 253, Bauliche Veränderungen in Reinhardtsgrimma 1804-1806. Von der Inneneinrichtung wird 1882 noch eine »Bülow-Stube« im Inventar verzeichnet.

Ebd., Nr. 253, Bauliche Veränderungen in Reinhardtsgrimma 1804-1806.

In diesem Zusammenhang sei auf eine grundlegende und gut recherchierte Arbeit hingewiesen, der entsprechende Inhalte zu entnehmen sind: Mertel, Thomas: Christian Friedrich Schuricht. Ein Baumeister des Klassizismus, Masterarbeit Universität Leipzig 1998, unveröffentlicht.

41 Hasche, Johann Christian (Hg.): Magazin der sächsischen Geschichte, Teil 1, Dresden 1784: Dresdner Baumeistergeschichte, S. 689

2 SächsHStA, 10505, Nr. 251

43 Bechter et al.: Handbuch der Deutschen Kunstdenkmäler. Sachsen - Neubearbeitung von: Dehio Georg - Handbuch der deutschen Kulturdenkmäler. Band 1, München 1996, S. 751.

4 Ebd. sowie Krepelin, Kirsten; Thränert, Thomas: Die gewidmete Landschaft. Spaziergänge und verschönerte Landschaft um Dresden, Worms 2011, S. 234.

Dokument aus der Turmkugel des Schlosses Reinhardtsgrimma, 23.06.1843, Verfasser: Pfarrer Paul Konstantin Brückner: "Herr Georg Konrad Ruschenbusch $[\ldots]$, der unsere unvergeßlichen Bauten ausgeführt hat z.B. ein ganz neues Gasthaus, eine Schäferei [...], ein Schießhaus der sogenannten Buschschenke gegenuber, wo ein schöner Koncertund Tanzsaal sich befindet $-[\ldots]$. 
46 Bechter 1996, S. 751 und Geller, Hans: Franz und Ferdinand Pettrich. Zwei sächsische Bildhauer au der Zeit des Klassizismus, Dresden 1955, S. 99-102. 47 SächsHStA, 10505, Nr. 251

48 Ebd., Nr. 547, Rechtshilfeersuchen des Amts Pirna wegen der Pachtstreitigkeiten zwischen Friederike Juliane Christiane von Bülow auf Reinhardtsgrimma und dem Pächter Johann Andreas Walther 1807-1810; SächsHStA, 10079 Landesregierung, Loc 13795/10; SächsHStA, 10062 Amt Pirna, Nr. 2167.

49 SächsHStA, 10505, Nr. 247, Testament von Friedrich Ludwig Ernst von Bülow (Abschrift) 1802.

50 SächsHStA, 10365 Grundherrschaft Liebstadt, Nr 2557. Zu den Belastungen durch die Freiheitskriege, s. Tinius 1956, S. 64-66.

51 Ihre Mutter Eleonora Charlotte Grote (1712-1781) war in erster, 1729 geschlossener Ehe mit Georg (1699-1737) verheiratet, in zweiter, 1741 geschlossener Ehe mit Wilhelm Albrecht Georg von Behr (1708-1773). Zu Friedrich August Otto, siehe: Vogell, F.: Versuch einer Geschlechtsgeschichte des hochadeligen Hauses der Herren Behr, Celle 1815, S. 125-127.

52 Die große Karte befindet sich im Foyer des Schlosses Reinhardtsgrimma, die Forstkarte in der Plansammlung des Landesamtes für Denkmalpflege Sachsen (Inv.-Nr. 1978-284).

53 Poenicke 1856, S. 163; SächsHStA, 10505, Nr. 163/16 Bau der Schäferei 1837/1838; Nr. 202, Schäfereiordnung; Nr. 68, Schäfereibuch. Siehe auch die Schafswollproben in 10505, Nr. 078/079. Schon 1801 wir vom Bau einer Schäferei berichtet, siehe SächsHStA 10505, Nr. 253.

54 SächsHStA, 10505, Nr. 288, Bauliche Veränderungen am Rittergut Reinhardtsgrimma 1847-1871.

55 Ebd., Nr. 509, Drei Skizzen zur baulichen Veränderung am Schloss Reinhardtsgrimma undatiert.

56 Drittes Dokument aus der Turmkugel des Schlosses Reinhardtsgrimma vom 14.07.1886, Verfasser R. B. Hoffmann, Pfarrer in Reinhardtsgrimma, in Grimmsches Heimatblatt, Heft Nr. 5, März/2010.

57 Kulturzentrum Erbgericht Reinhardtsgrimma e.V. (Hg.): Festschrift des 80o-jährigen Jubiläums Reinhardtsgrimmas "Ein Dorf im Wandel der Zeit 1206-2006. Dorf und Schloß Reinhardtsgrimma in Rahmen der historischen Ereignisse«, bezüglich des Testaments von Friderike Juliane Christiane verehl. Ruschenbusch, s. S. 21 und 54-56.

58 In der im Erbgericht in Reinhardtsgrimma gezeigten Ausstellung zu den Ruschenbuschs aus dem Jah 2006 wurde das in Familienbesitz befindliche Testament in einer Abbildung gezeigt.

9 SächsHStA, 10505, Nr. 530, Kaufvertrag zwischen Georg Konrad Ruschenbusch und seiner Frau Fr derike Juliane Christine R., geb. von Bülow 1831.

6o Die von Bülowsche Gruft wurde 1963 abgebrochen. Siehe hierzu: Heimatverein Reinhardtsgrimm (Hg.): Die Grüfte der Kirche, in: Grimmsche Heimatblätter, Heft Nr. 26, 6/2015, S. 15.

61 SachsHStA, 10505, Nr. 353, Familiengruft 1865-1866. Eine Anfrage an die Kreisdirektion Dresden lief schon 1864. Zur Gräberpflege s. SächsHStA, 10505, Nr. 264, Forst- und Gärtnereiangelegenheiten von Reinhardtsgrimma 1911-1940.

62 Ebd., Nr. 73, Georg Conrad und Gotthold Ruschenbusch Stiftung, 1866 dort auch Statuten. Die Stiftung stellte eine Versorgungseinrichtung da, in die man sich einkaufen konnte. In den Unterlagen finden sich Namen und Daten zahlreicher Gutsarbeiter.

Ebd., Nr. 26, Register über das bewegliche Inventar des Rittergutes Reinhardtsgrimma 1874

64 Am Ende, Christian G. Ernst: Die Ökonomische Gesellschaft im Königreiche Sachsen, Dresden 1884, Widmungsblatt an Aster; sowie S. 40: Eintritt Asters in die Gesellschaft 1871

65 SächsHStA, 10505, Nr. 288. und $\mathrm{Nr}$. 433 , Baukostenvechnign tranerdass die Brennerei 1865 eingegangen sei.

Ebd., Nr. 26, 24, 35.

68 Ebd., Nr. 35, Flurbuch 1875

69 Ebd., Nr. 35

7 Ebd., Nr. 365, Forstangelegenheiten 1921-1928.

erat Johann Maximilian Nitzsche,

72 Ebd., Nr. 35, fol.10.

${ }_{3}$ Ebd., Nr. 66, Einnahmen und Ausgaben der Gutswirtschaft, u. a. an Pacht, Zinsen, Jagden, Obstwirtschaft, Grasnutzung 1886-1888. Die Jagd war ehe nebensächlich: 1884 wird einmal ein Sechsende geschossen und immer wieder Geflügel (u.a. der Wachtelkönig) erlegt.

74 Ebd., Nr. 135, Pachtvertrag zwischen Eleonore Christiana von Tettau, geb. von Berbisdorf, auf Reinhardtsgrimma und Georg Abraham Sieger über das Rittergut Reinhardtsgrimma 1716-1731, und Ebd., Nr. 364, Hauptinstruktion für den Ökonomieinspektor auf Reinhardtsgrimma 1874.

75 Ebd., Nr. 288, die Maulwürfe in Ebd., Nr. 42.

76 Ebd., Nr. 37, Lohnjournal 1867-1875.

77 Ebd., Nr. 26 (betrifft 1912).

78 Ebd., Nr. 36 , Grundbuch 1865-1888.

Ebd., Nr. 36 und Ebd., Nr. 389, Verkauf des Rittergutes Reinhardtsgrimma von Frau Nitzche an Max imilian Senfft von Pilsach 1907-1909.

80 Tinius, Heinz: Ortchronik von Reinhardtsgrimma, 1960, S. 86.

81 Dokument aus der Turmkugel des Schlosses Rein hardtsgrimma vom 14.07.1886, Verfasser R. B. Hoffmann, Pfarrer in Reinhardtsgrimma, in: Grimmsche Heimatblätter, Heft Nr. 5, März/2010.

82 SächsHStA, 10505, Nr. 339, Bauliche Veränderungen, Reparaturen, Um- und Neubauten auf dem Rittergut Reinhardtsgrimma 1889-1902.

83 Ebd., Nr. 10, Leute- und Gespannbuch 1888-1889.

Ebd., Nr. 389, Ankauf von Reinhardtsgrimma und Bodengut 1907-1908

5 Über den Zustand (vor allem des kaputten Daches) gab es eine gerichtliche Vorladung der Verkäuferin die jedoch in einem Vergleich geendet haben muss, da nichts gesondert im Archiv festgehalten wurde.
86 Tinius 1956, S. 82; die Gaben von Nitzsche wie auch die von Senffts wurden durch Inflation und Währungsreform bald hinfällig.

87 Gothaisches Genealogisches Taschenbuch der Adeligen Häuser, Jg. 52, 2. Teil, 1902, S. 782 .

88 Landeshauptarchiv Sachsen-Anhalt, Außenstelle Wernigerode, H 240, Nr. 1503. Das Erbe lief dabei über die die Mutter beider Senfft-Kinder, Auguste geb. von Helldorff (1828-1890).

89 SächsHStA, 10505, Nr. 419, Vermietung und Instandsetzung des Schlosses Böhlen durch General Senfft von Pilsach auf Reinhardtsgrimma 19101920. Zwischen 1901-1920 wird zudem ein Pächter namens Töpfer genannt.

90 Ebd., Nr. 75.

91. Die im Gutsarchiv vorhandenen Alben mit Fotografien von führenden Militärpersonen, die man in die 1870er Jahre nach Hannover verorten kann in die ten auf diese Verbindungen hin noch, müsten auf diese 10505, Nr. 393, Testament von Hugo Senfft von Pilsach (Abschrift) 1900.

92 Für diese Hinweise sei René Dessing gedankt; im Detail, siehe: Lennep, Henrick S. van: Genealogie van de familie Teding van Berkhout, Koninklijk Nederlandsch 2014. This book is part of the serie Studies published by the Royal Dutch Society for Gender and Heraldry. Volumme XXI, S. 105-110.

93 SächsHStA, 10505, Nr. 92, Adressbuch der Gutsverwaltung 1906. Als Beispiel: Senfft suchte die 1917 geborene Hündin Alta von Tauteneck für den Revierforster Hetze als Begleithund aus. Sie wurde 1923 von Taps von Harachstal vom "Gebrauchshundezwinger Bürgerwiese« gedeckt. Senffts persönlicher Dackel Bob, der auch im 20. Band des TeckelStammbuches auftaucht, wurde 1909 von Alice von Griesheim in Kalübbe erworben. Zudem kam 192 die Hündin Gudrun ins Haus, die man vom Schwager, dem Grafen Werner von der SchulenburgHeßler aus Schloss Vitzenburg holte.

94 Knight, Roger G. Commodities and Colonialisation. The Story of Big Sugar in Indonesia, 18801942, Leiden/ Boston 2013, S. 133. Zur Genealogie Nederlands AdelboekBand 79, 1988, S. 489. D Vermögen der Eltern (gest. 1917/27) wurde auf 1,5 Mio. niederländische Gulden geschätzt, wobei Alpheda in Erbang ine Gu Alpheda in Erbent A

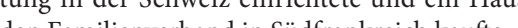

SächsHStA, 10505, Nr. 477, Gutswirtschaftsangele-

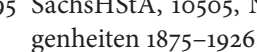

genheiten 1875-1926.
6 Ebd., Nr. 19, Feldbestellungs- und Ernteregister mit Fruchtfolgeplan 1921-1945.

97 Ebd., Nr. 104, Baurechnungen 1907-1909. Die historische Umrechnung liegt im 10-2ofachen Bereich des Nennwertes.

98 Donath, Matthias: Gustav Robert Frölich, in: Institut für Sachsische Geschichte und Volkskunde e. (Hg.): Sächsische Biografie, Online-Ausgabe: http:// www.isgv.de/saebi/ (Zugriff am 27.4.2020); Zu
Frölich und den Umbauten am Dresdner Schloss, siehe: Magirius, Heinrich: Das Residenzschloss zu Zeit König Alberts - Äußere Neugestaltung unter Gustav Dunger und Gustav Frölich zwischen 188 und 1901, in: Landesamt für Denkmalpflege Sachse (Hg.): Das Residenzschloss zu DresdenBand 3 Petersberg 2020, S. 409-447

http://www.geschichte-der-fliese.de/RgUtrechter. html (Zugriff am 29.4.2020)

SachsHStA, 105050, Nr. 104; Gahn, Wolfgang: »... Sammlung ohne Rivalen in der Welt ...« August Kuhnscherf \& Söhne. Eine Dresdner Schlosserfirm und ihre Sammlung von Schlosser- und Kunstschmiedearbeiten, in: Stadtmuseum Dresden (Hg.) Dresdner Geschichtsbuch 7, Altenburg 2001, S. 115ft. SächsHStA, 10505, Nr. 509, Drei Skizzen zur baulerung am Schloss Reinhardtsgrimma undatierte Akte.

02 Es gibt zwei Grundrisse des Schlosses aus der Zeit um 1907/08, die Eintragungen in Holländisch aufweisen. Möglicherweise wurden die Umbaumaß nahmen auch bei der niederländischen Familie besprochen. Der Einbau der Kacheln aber auch die Verwendung der Leinwandtapeten sprechen dafü dass man sehr wohl auf dortige Vorbilder rekurrierte.

Mitgeteilt von seiner Enkelin Margarethe vo Oheimb als Foto eines Zeitungsausschnitts, aus: Unbekannte Zeitung, bezeichnet »Nr. 370, S. 6《 [Anfang August 1931].

SächsHStA, 10505, Nr. 233, Feldscheune 1827. Die Bestellungen scheinen über Senffts Sohn zu laufen, der sich beim Schwager Hohenthal in Dölkau aufhielt.

105 Ebd., Nr. 20, Geld- und Arbeitsregister 1920-1921. 106Ebd., Nr. 391, Reparaturen und bauliche Veränderungen am Forsthaus in Reinhardtsgrimma 1927. "Wilhelm Reichel studierte in Zittau Architektur und war Schöpfer wichtiger Bauten des Umkreises, u.a. der Volksschule in Glashütte 1902«; sein Unternehmen wurde 1880 gegründet und existiert auch heute noch, siehe: http://www.heimatverein-cunnersdorf.de/ortsbesichtigung/langestr_von_glash_ bis_ende/index.html (Zugriff im Juni 2020).

Kulturzentrum Erbgericht Reinhardtsgrimma e.V.

(Hg.): Festschrift des 80o-jährigen Jubiläums Reinhardtgrimmas "Ein Dorf im Wandel der Zeit 1206 2006. Dorf und Schloß Reinhardtsgrimma im Rahmen der historischen Ereignisse", bezüglich de Familie Senfft von Pilsach, s. S. 33. Siehe auch di Schilderung von Hugo von Senfft in: Lennep 2014. Zur Geschichte nach 1945 äußert sich polemisch Tinius 1956.

http://www.reinhardtsgrimma.hiller-musik.de/ schloss/schlossgesch.html (Zugriff am 15.07.2020).

Bankmann, Karl: Fritz Steudtner - fünf Jahrzehnte Architekt in Dresden, Diss. TU Dresden, 2020, S. $161 f f$

Landesamt für Denkmalpflege Sachsen, Topografisches Aktenarchiv, Akte Nr. 2-4, Schlossgasse Glashütte OT Reinhardtsgrimma, Schloss 1952-1997. 